REVIEW ARTICLE

DOI: $10.1038 / s 41467-018-02838-4$

\title{
Expanding frontiers in materials chemistry and physics with multiple anions
}

\author{
Hiroshi Kageyama (10 ${ }^{1}$, Katsuro Hayashi (1) ${ }^{2}$, Kazuhiko Maeda (iD) ${ }^{3}$, J. Paul Attfield (10 ${ }^{4}$, Zenji Hiroi (iD) ${ }^{5}$, \\ James M. Rondinelli iD ${ }^{6} \&$ Kenneth R. Poeppelmeier (iD ${ }^{7}$
}

During the last century, inorganic oxide compounds laid foundations for materials synthesis, characterization, and technology translation by adding new functions into devices previously dominated by main-group element semiconductor compounds. Today, compounds with multiple anions beyond the single-oxide ion, such as oxyhalides and oxyhydrides, offer a new materials platform from which superior functionality may arise. Here we review the recent progress, status, and future prospects and challenges facing the development and deployment of mixed-anion compounds, focusing mainly on oxide-derived materials. We devote attention to the crucial roles that multiple anions play during synthesis, characterization, and in the physical properties of these materials. We discuss the opportunities enabled by recent advances in synthetic approaches for design of both local and overall structure, state-of-theart characterization techniques to distinguish unique structural and chemical states, and chemical/physical properties emerging from the synergy of multiple anions for catalysis, energy conversion, and electronic materials.

$\mathrm{T}$ he continuing growth of many modern technologies is driven by the development of functional solid-state materials, such as metal oxides, fluorides, and nitrides that adopt a range of structural types and compositions. The accumulation of knowledge based on experimental data (or at times "chemical intuition") and computational modeling and validations has led to extensive knowledge of these "single-anion" materials and affords further prediction of properties. Most of these results derive from variations in metal cation chemistry, as opposed to the anion, when examining structure-property relationships.

A multiple or mixed-anion compound is a solid-state material containing more than one anionic species in a single phase, such as oxyfluorides (oxide-fluoride) and oxynitrides (oxidenitride). Unlike oxides, which exhibit diverse chemistries and structures often known from mineralogy, the structures of most mixed-anion compounds, among other aspects, are less explored with much to learn. This is readily seen when looking at the local structure of these compounds where the metal cation is bonded to more than one anionic ligand to form a heteroleptic polyhedron (Box 1). The different anionic characteristics, such as charge, ionic radii, electronegativity, and polarizability (Table 1) add new dimensions to control and tune the

\footnotetext{
${ }^{1}$ Graduate School of Engineering, Kyoto University, Nishikyo-ku, Kyoto 615-8581, Japan. ${ }^{2}$ Department of Applied Chemistry, Kyushu University, Fukuoka 8190395, Japan. ${ }^{3}$ Department of Chemistry, School of Science, Tokyo Institute of Technology, 2-12-1-NE-2 Ookayama, Meguro-ku, Tokyo 152-8550, Japan. ${ }^{4}$ Centre for Science at Extreme Conditions, University of Edinburgh, EH9 3FD Edinburgh, UK. ${ }^{5}$ Institute for Solid State Physics, University of Tokyo, Kashiwanoha 5-1-5, Kashiwa, Chiba 277-8581, Japan. ${ }^{6}$ Department of Materials Science and Engineering, Northwestern University, Evanston, IL 60208, USA. ${ }^{7}$ Department of Chemistry, Northwestern University, Evanston, IL 60208, USA. Correspondence and requests for materials should be addressed to H.K. (email: kage@scl.kyoto-u.ac.jp)
} 


\section{Box 1. I From oxides to mixed-anion compounds}

Applications of oxides date back to prehistoric times, when our ancestors found useful properties from natural stones including, e.g., arrowheads, magnets, pigments, gems, and even medicines. Subsequent efforts have been devoted to improvements and hunting for new functions. The 20th century was a prosperous era, with discoveries of synthetic oxides that sustain modern technology, as exemplified by the ferroelectric $\mathrm{BaTiO}_{3}$, yttriastabilized zirconia (YSZ) for solid oxide fuel cells, and $\mathrm{Li}_{x} \mathrm{MnO}_{2}$, a cathode material for lithium batteries. The successful story of oxides (and other single-anion compounds, such as fluorides, nitrides, and chlorides) is largely due to their stability and ease of synthesis, along with development of structural characterization techniques, such as X-ray diffraction. Numerous inorganic compounds (51,856 oxides, 1581 nitrides, 2978 fluorides in the Inorganic Crystal Structure Database (ICSD, https://icsd.fiz-karlsruhe.de), as of 5 October 2017) have been reported, most of which can be prepared by high-temperature solid-state reactions over $1000^{\circ} \mathrm{C}$. A result of extensive research over the last century is that new materials accessible by 'heat and beat' exploration of new cation combinations may be exhausted soon.

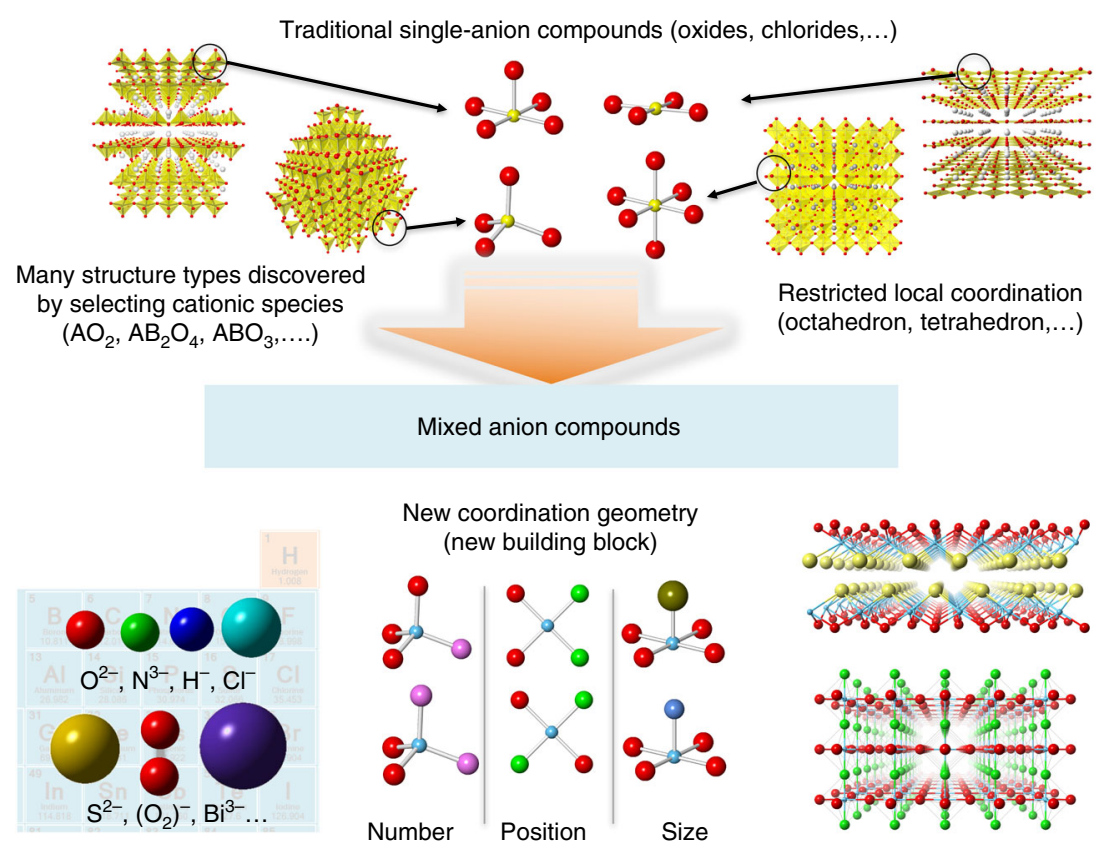

Focusing on the anions within a compound offers a solution to this problem. This can enhance the possible combinations of elements, but also offers more diversity. Cation-based compounds are based on common coordination polyhedra as building units (e.g., $\mathrm{CuO}_{4}$ square planes). However, if several oxide anions are replaced with other anions, new and unusual coordination geometries may result. When these polyhedra, as new building blocks, are arranged to form an extended array, one can expect enhanced properties or fundamentally new phenomena. Since anions exhibit different characteristics (e.g., ionic radii, valence, polarizability, and electronegativity), selecting different anions can introduce a new dimension of flexibility for materials design and function. Despite such possibilities, the number of mixed-anion compounds available are limited: the number of recorded materials in ICSD are 1266 for oxyfluorides, 612 for oxynitrides, 47 for oxyhydrides, 655 oxychalcogenides, and 312 oxypnictides. Note that mixed-anion compounds do not necessarily possess a heteroleptic coordination geometry around a transition metal. For example, a number of structures are comprised of alternating layers, each with a homoleptic coordination by a different anion, as found in $\mathrm{Sr}_{2} \mathrm{MnO}_{2} \mathrm{Cu}_{1.5} \mathrm{~S}_{2}$ with alternating $\mathrm{Sr}_{2} \mathrm{MnO}_{2}$ and $\mathrm{Cu}_{1.5} \mathrm{~S}_{2}$ layers $^{102}$.

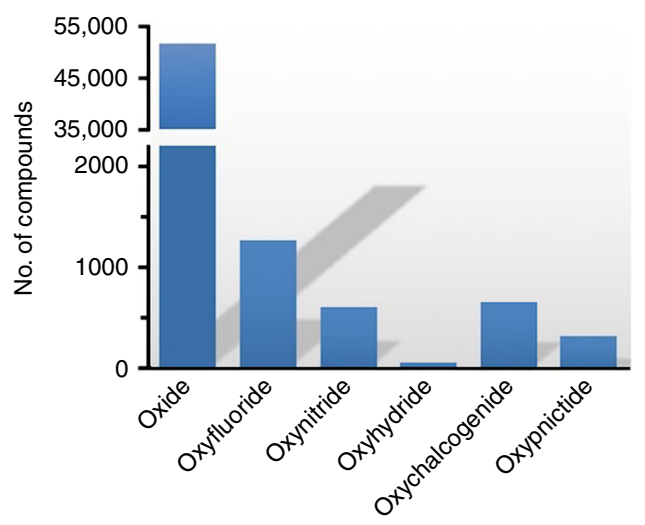

Although some excellent overviews of mixed anion compounds have been provided $2,5,12,16,81,82,102$, each covers relatively narrow range of materials and disciplines. This review article is attempting to capture the broader fundamentals of these materials and draw new insights among materials classes. 
Table 1 Basic parameters of anions-forming elements and their ions

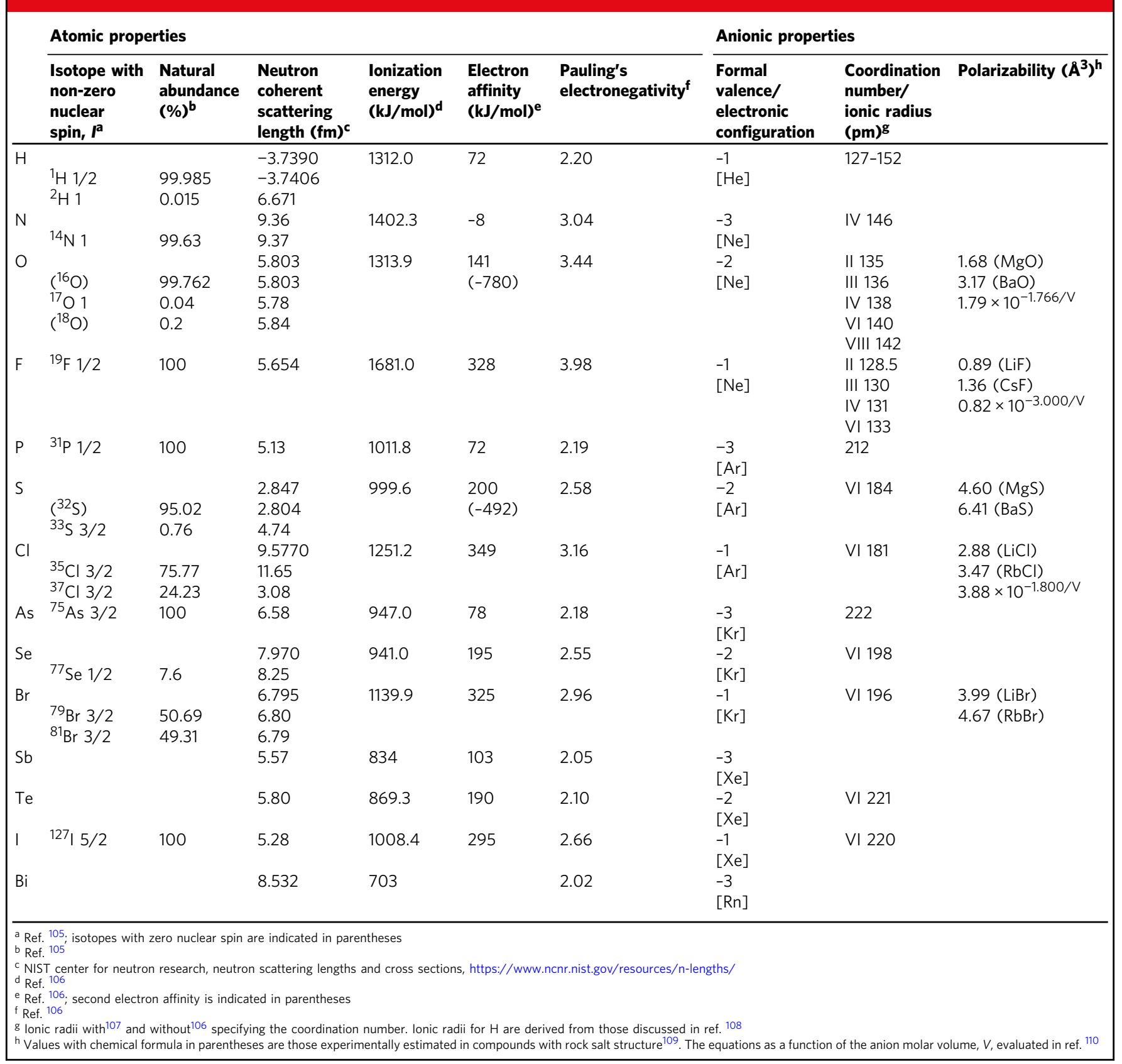

electronic and atomic structure of materials, which may support phenomena inaccessible to a single-anion analog.

Such anion-centered chemistry and physics is still in its infancy; there is much unexplored space, making it perhaps the most untapped field of materials sciences and giving new challenges and opportunities. In this review, we aim to describe the current status and scope, as well as outline future prospects and challenges surrounding mixed-anion (mostly oxide based) compounds, in particular, focusing on crucial roles of multiple anions in synthesis, characterization, and chemical and physical properties. Note that we had to be selective in materials and references because of the limited space. We provided mainly reviews or selected references, which could be an entry point to the literature search for readers who need additional information.

\section{Mixed-anion directed strategies}

Understanding of mixed-anion compounds is still growing, but recent studies have unveiled several key features that are otherwise inaccessible in traditional single-anion compounds, as summarized in Fig. 1. Replacing oxide ligands in coordination octahedra or tetrahedra with other anions can differentiate the binding energy (Fig. 1e), which may benefit chemical reaction and anionic diffusion (Fig. 1f). It might also cause a (local) symmetry breaking (Fig. 1d) or create a cis/trans degree of freedom (Fig. 1c). The latter is a familiar ingredient in coordination chemistry, but less so in solid-state chemistry. Additionally, the crystal field splitting (CFS) can be tuned to the extent that is only allowed in coordination complexes, while retaining the original polyhedral shape and connectivity (Fig. 1a). An extensive modification of 
a

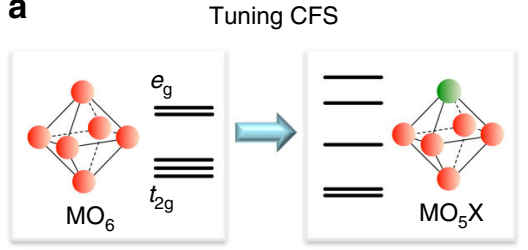

C

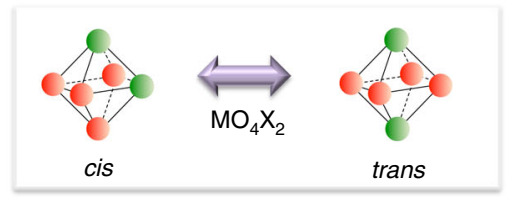

e

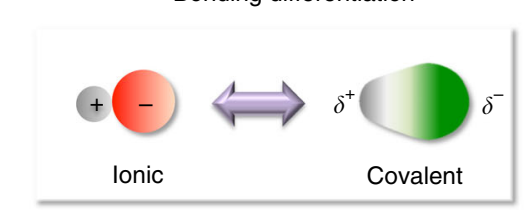

g

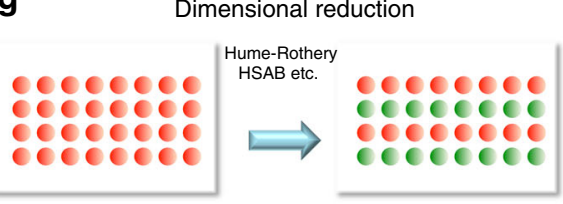

b

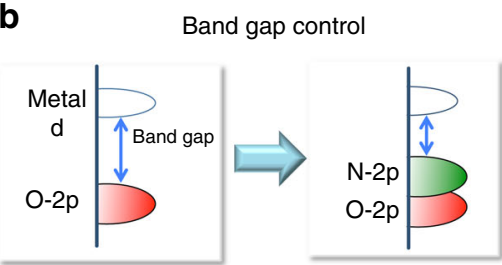

d

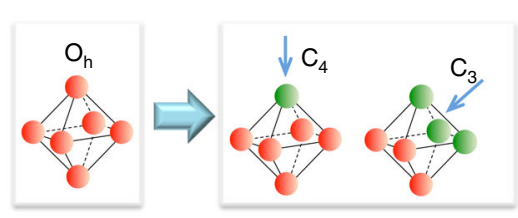

f

Anion diffusion and reaction

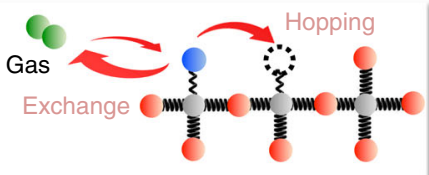

h

Molecular anions
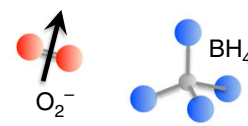

$\mathrm{NCN}^{2-}$

Fig. 1 What mixed-anion compounds can do (Concepts 1a-1h). a Extensive tuning of CFS. Replacement of one oxygen with a different anion allows extensive tuning of CFS even when the octahedron stays rigid. b Non-oxide anion with lower electronegativity (vs. oxide) in semiconductors raises the VBM and narrows the band gap, affording visible light applications like water splitting catalysis ${ }^{51,52}$ and pigmentation ${ }^{49}$. c Local degree of freedom. An $\mathrm{MO}_{4} \mathrm{X}_{2}$ octahedron has cis and trans geometries, major parameters widely exploited in coordination chemistry, but less so in solid-state chemistry. When $\mathrm{MO}_{4} \mathrm{X}_{2}$ octahedra with cis or trans preference are connected to form an extended lattice, various non-trivial structures can appear, some of which have 'correlated disorder'34,38. d Local coordination asymmetry. The $\mathrm{O}_{\mathrm{h}}$ symmetry of the rigid octahedron is lost by replacing one and three ligands, leading to $\mathrm{C}_{4}$ and $\mathrm{C}_{3}$ symmetry. e, $\mathbf{f}$ Covalency and ionicity can be tuned to acquire desired functions. A weakly bonded ligand to a metal centre can generate functions related to anion diffusion (anionic conductivity) and anion reaction at the surface (catalysis), whereas the structural stability is secured by strongly bonded counter ligands ${ }^{13,69,70}$. g Dimensional reduction. Alternate stacking of layers of different anions, which can be rationalized utilizing, e.g., HSAB concept and Hume-Rothery rules ${ }^{78}$, have potential to enhance two-dimensionality, leading to novel properties, including high- $T_{\mathrm{c}}$

superconductivity ${ }^{81,82,103}$. h Inclusion of molecular anions further widens possibilities. Available parameters, include anisotropic shape, magnetic moment (e.g., $\mathrm{S}=1 / 2$ moment in $\mathrm{O}_{2}^{-}$) and additional (anisotropic) bonding (e.g., bonding to hydrogen in $\mathrm{BH}_{4}^{-}$) $99-101$

band (electronic) structures is also noteworthy, leading to a reduced dimensionality (Fig. 1g) and an upward shift of valence band maximum (VBM) (Fig. 1b).

Oxyhydrides (oxide hydrides), containing oxide and negatively charged hydride $\left(\mathrm{H}^{-}\right)$anions, are rare but can be remarkable materials. Several features specific to hydride are given in Fig. 2. Hydrogen is the simplest (and lightest) element with one electron and one proton, giving the hydride anion distinct characteristics that differentiate it from other anions. For example, its bipolar nature and moderate electronegativity allow covalent, metallic, and ionic bonding, depending on the electronegativity of the element with which hydrogen bonds. This is schematically represented by the unconventional periodic table of elements (Fig. 2 b) ${ }^{1}$, where values of electronegativity, ionization potential, and electron affinity are shown in the upper left, lower left, and lower right corner of each box. Related to this, the extraordinary flexibility in size of hydride (Fig. 2a) and possible reactions involving the zwitterionic nature (Fig. 2d) may bring about unprecedented functions. The flexible nature of hydride is also evident in its polarizability, as the refractive index of $\mathrm{LiH}$ (1.985) is significantly larger than that of $\operatorname{LiF}$ (1.392) despite the fewer number of electrons. Finally, $\mathrm{H}^{-}$is the only anion which does not possess $p$ orbitals in the valence shell. The lack of $p$ orbitals in the outermost shell (Fig. 2c) significantly distinguishes its chemical bonding nature and its magnetic interaction with other anions.

\section{Synthesis beyond heat and beat}

Conventional inorganic materials are mostly oxides, due to the fact that the Earth's atmosphere contains mainly reactive oxygen (and inert nitrogen). Thus, metal oxides are conventionally synthesized by high-temperature solid-state reactions, sometime called 'heat and beat' (or 'shake and bake') processing. A major difficulty in preparing mixed-anion compounds in the same way lies in the differing volatilities of precursors (oxides, chlorides, hydrides, and so on), so simple heating of mixed starting reagents often ends up with single-anion compounds, though some can be prepared in air (e.g., $\mathrm{LaCl}_{3}+0.5 \mathrm{O}_{2} \rightarrow \mathrm{LaOCl}+\mathrm{Cl}_{2}$ ). For this reason, the preparation of mixed anion compounds often requires controlled atmospheres, such as in vacuum or under various flowing gases $\left(\mathrm{Cl}_{2}, \mathrm{~F}_{2}, \mathrm{NH}_{3}, \mathrm{CS}_{2}\right.$, and so on) (Fig. 3a) or exploits alternative synthesis methods, including soft-chemistry (Fig. 3b), solvothermal synthesis, or thin-film growth techniques (Fig. 3c) and high-pressure synthesis (Fig. 3d). 
a

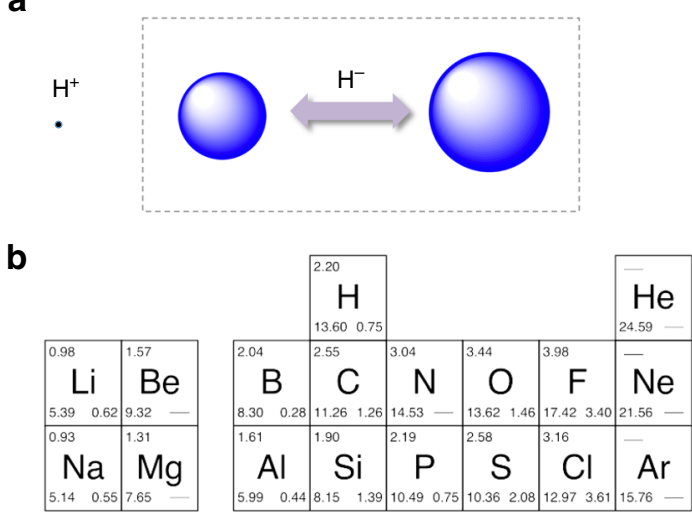

d

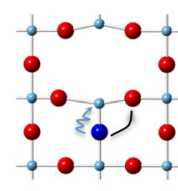

$\mathrm{H}^{-}$

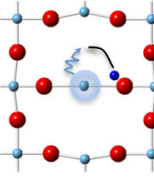

$\left(2 \mathrm{e}^{-}+\mathrm{O}_{\mathrm{OH}^{\prime}}\right)$

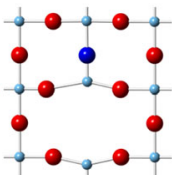

$\mathrm{H}^{-}$
C
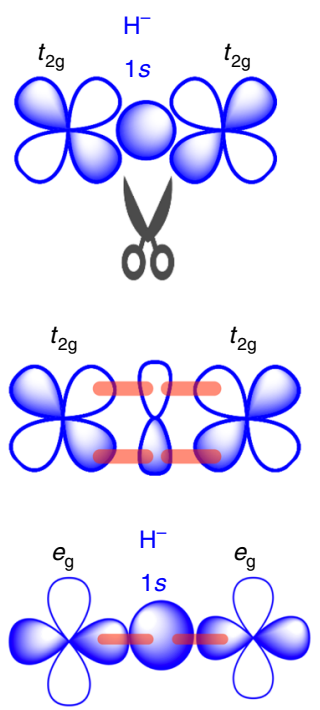

Fig. 2 Specific features of hydride anion $\mathrm{H}^{-}$(Concepts 2a-2d). a As opposed to other anions, $\mathrm{H}^{-}$is highly flexible in size (right, exaggerated for clarity), with ionic radii of $\sim 130-153 \mathrm{pm}$ found in metal hydrides. This means that $\mathrm{H}^{-}$(or more precisely $\mathrm{H}^{\delta-}$ ) can adapt itself to a given local environment. This appears to hold for oxyhydrides ${ }^{12}$ and is important for the hydride detection and characterization by ${ }^{1} \mathrm{H}-\mathrm{NMR}$ (Fig. $4 \mathrm{~b}$ ) ${ }^{44}$. A high-pressure study revealed that $\mathrm{H}^{-}$is extremely compressible ${ }^{9}$. b A periodic table of elements, taken from ref. ${ }^{1}$. Justifications of hydrogen positioning above carbon arise from a half filled outer shell and a similarity in electronegativity to group IV elements (C, Si...). c The lack of $\pi$ symmetry in $\mathrm{H}^{-}$1s orbital allows this ligand to act as a " $\pi$-blocker" (or orbital scissors) with respect to $t_{2 g}$ orbitals of a transition metal, leading to the dimensional reduction in Fig. $1 g^{9,89}$. A fairly strong $\sigma$ bonding is suggested between $e_{g}$ and $\mathrm{H}^{-} 1 s$ orbitals ${ }^{8}$. d Hydride anion is regarded as a highly labile ligand, which, combined with the electron donating nature of hydride, allow versatile opportunities for oxyhydrides, including hydride anion conductivity ${ }^{70}$, topochemical reactions ${ }^{13,14}$, and catalysis ${ }^{95}$. Shown in this panel is a theoretically proposed non-trivial hydride diffusion process in $\mathrm{SrTiO}_{3}{ }^{104}$, involving electron transfer from/to the titanium cation, being analogous to the so-called proton coupled electron transfer (PCET) - "electron coupled hydride transfer" (ECHT). Fixation of such transient "two-electron released state" is realized in $\mathrm{H}^{-}$ion-doped $12 \mathrm{CaO} \cdot 7 \mathrm{Al}_{2} \mathrm{O}_{3}$ by UV-light excitation ${ }^{47}$

For example, a high-temperature ammonolysis reaction (under $\mathrm{NH}_{3}$ flow) is employed ${ }^{2}$, instead of inert $\mathrm{N}_{2}$, to obtain many oxynitride semiconductors, including $\mathrm{AMO}_{2} \mathrm{~N}(\mathrm{~A}=\mathrm{Ba}, \mathrm{Sr}, \mathrm{Ca}$; $\mathrm{M}=\mathrm{Ta}, \mathrm{Nb})$ with a high dielectric constant due to the larger polarizability of nitrogen (Fig. 1e) $)^{3}$. However, the ammonolysis reaction involves the dissociation of $\mathrm{NH}_{3}-\mathrm{N}_{2}$ and $\mathrm{H}_{2}$ (Fig. 3a) and thus provides a highly reducing atmosphere, which gives a certain constraint on available metals. To increase the reactivity of ammonia, a microwave oven is used to generate an ammonia plasma $^{2}$.

The high reactivity of the anionic species, often gaseous in elemental form, can conversely be an advantage in tailoring anions in extended solids at low temperature. Topochemical insertion and exchange reactions (Fig. 3b), which provide metastable mixed-anion phases from precursors (typically oxides) in a rational, chemically designed manner, have been developed over the last two decades ${ }^{4}$. A proper choice of reagents and host structures is essential in directing reactions in a desired way. Consider for example oxyfluorides: a $F_{2}$ treatment can give an oxidative fluorination involving F-intercalation (e.g., $\mathrm{LaSrMn}^{3}$ ${ }^{+} \mathrm{O}_{4} \rightarrow \mathrm{LaSrMn}{ }^{5+} \mathrm{O}_{4} \mathrm{~F}_{2}$ ), while poly(tetrafluoroethylene), known as Telfon, acts as a reductant and may lead to reductive fluorination involving O/F-exchange (e.g., $\mathrm{RbLaNb}_{5,6}{ }_{2} \mathrm{O}_{7} \rightarrow \mathrm{RbLaNb}^{4.5+}{ }_{2} \mathrm{O}_{6} \mathrm{~F}$ ) 5,6

The hydride anion is strongly reductive in nature, with a large standard redox potential of $-2.2 \mathrm{~V}\left(\mathrm{H}^{-} / \mathrm{H}_{2}\right.$ vs. SHE), so a transition metal oxyhydride appears impossible to stabilize. However, topochemical reaction using metal hydrides, such as $\mathrm{CaH}_{2}$ has opened a new avenue, yielding as the first example $\mathrm{LaSrCoO}_{3} \mathrm{H}_{0.7}$ $\left(\mathrm{Co}^{1.7+}, d^{7.3}\right)$ in $2002^{7}$. Density functional theory (DFT) calculations revealed the presence of fairly strong $\sigma$ bonding between $\mathrm{Co} e_{\mathrm{g}}$ and $\mathrm{H} 1 s$ orbitals $^{8}$. On the other hand, the formation of $\mathrm{BaTiO}_{2.4} \mathrm{H}_{0.6}\left(\mathrm{Ti}^{3.4+} ; d^{0.6}\right), \mathrm{SrVO}_{2} \mathrm{H}\left(\mathrm{V}^{3+} ; d^{2}\right)$, and $\mathrm{SrCrO}_{2} \mathrm{H}\left(\mathrm{Cr}^{3+} ; d^{3}\right)$ is not readily rationalized since Ti/V/Cr $t_{2 \mathrm{~g}}$ and $\mathrm{H} 1 s$ orbitals are orthogonal (Fig. $2 \mathrm{c})^{9-11}$. Since all the known transition-metal oxyhydrides exist with alkali and alkaline earth elements ${ }^{12}$, inclusion of any highly electropositive cation appears to be needed to make hydrogen with its moderate electronegativity (Fig. 2b) become negatively charged. This may explain why $\mathrm{TiO}_{2}$ does not incorporate hydride.

The observation of $\mathrm{H} / \mathrm{D}$ exchange in $\mathrm{BaTiO}_{2.4} \mathrm{H}_{0.6}$ when heated in deuterium gas at $\sim 400{ }^{\circ} \mathrm{C}$ indicates the labile nature of $\mathrm{H}^{-}$ (Fig. 1f $)^{10}$. The lability of hydride in $\mathrm{BaTiO}_{2.4} \mathrm{H}_{0.6}$ (and other oxyhydrides) enables further topochemical anion exchange reactions (Fig. 3b) ${ }^{11,13,14}$. When $\mathrm{BaTiO}_{2.4} \mathrm{H}_{0.6}$ is used as a precursor, the ammonolysis reaction temperature $\left(>1000^{\circ} \mathrm{C}\right)$ is remarkably lowered to $350^{\circ} \mathrm{C}$, yielding $\mathrm{BaTiO}_{2.4} \mathrm{~N}_{0.4}{ }^{13}$. Even $\mathrm{N}_{2}$ flow at $400^{\circ} \mathrm{C}$ gave the same product, demonstrating the ability of $\mathrm{H}^{-}$to activate the nitrogen molecule. This hydride exchange chemistry is general, yielding other mixed-anion compounds, such as oxide-hydride-hydroxide $\mathrm{BaTiO}_{2.5} \mathrm{H}_{0.25}(\mathrm{OH})_{0.25}{ }^{14}$.

Solvothermal synthesis is a synthetic method in which reactions occur in solution (i.e., water in the case of hydrothermal synthesis) inside a sealed vessel at temperatures near the boiling point of the solvent and pressures greater than atmospheric pressure $^{15}$. Liquid-phase transport of the reactants allows for rapid nucleation and subsequent growth of a crystalline product with controlled morphology. This method produces crystals at lower temperatures and on shorter timescales than typical solidstate reactions. It also increases the likelihood of formation of 


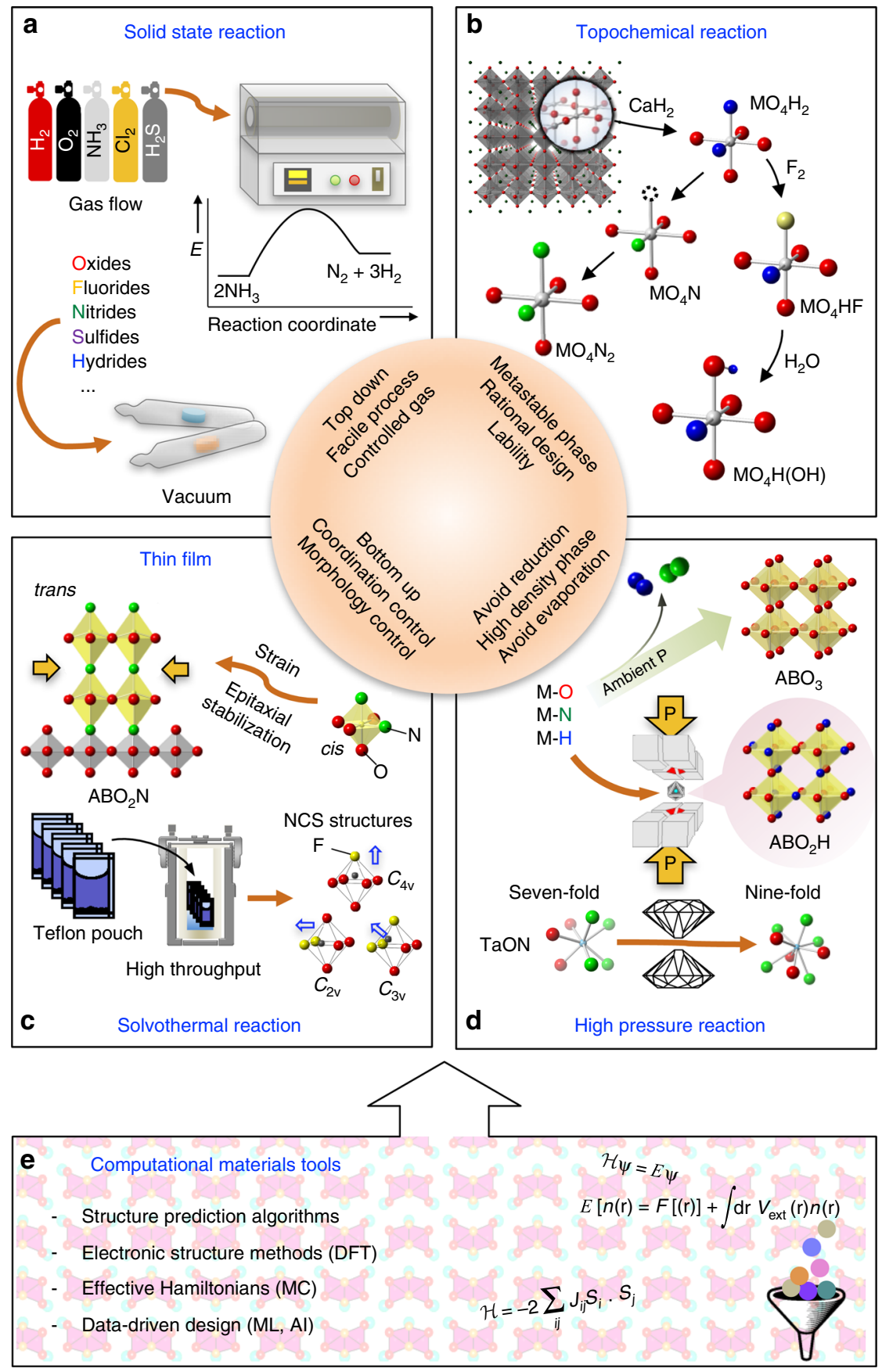

Fig. 3 Synthetic approaches for mixed anion compounds. a Traditional high-temperature solid-state reactions. Controlled atmospheres, such as flowing gases ( $\mathrm{NH}_{3}, \mathrm{Cl}_{2}, \mathrm{CS}_{2}$, and so on) and in a vacuum are often necessary. Gas-phase or surface reactions may be important. For example, owing to the dissociation of $\mathrm{NH}_{3}$ to $\mathrm{H}_{2}$ and inert $\mathrm{N}_{2}$ at elevated temperatures, processing conditions, such as an ammonia flow rate need to be carefully chosen. $\mathbf{b}$ Topochemical reactions to allow a rational design of structures (Fig. 1f). Low-temperature treatment of oxides with some reagents cause different anions to insert or exchange while maintaining the structural features. Multistep reactions have been also accessible ${ }^{13,14}$. c Epitaxial thin film growths and solvothermal reactions as a bottom-up process. Chemical bonding from ions of a substrate lattice yield metastable phases ${ }^{19}$. Local geometry can be manipulated by applying tensile or compressive strain from the substrate 20,21 . Solvothermal reactions offer an opportunity to prepare compounds with well-defined local structures. High throughput screening is possible with the Teflon pouch approach. d High-pressure reactions. High pressure can prevent some reagents from dissociation or evaporation (upper) $22-26,41$, and also stabilize dense structures (lower) ${ }^{27}$. e Computational tools. In particular, the rapid advancement of computational methods provides unprecedented opportunities for predicting and understanding mixed-anion compounds. DFT $=$ density functional theory, $\mathrm{MC}=$ Monte Carlo, $\mathrm{ML}=$ machine learning, $\mathrm{Al}=$ artificial intelligence

mixed-anion compounds (e.g., halide hydroxides, oxyhalides), which are often unfavored at higher temperatures. Solvothermal syntheses have been very successful in producing materials with acentric coordination environments that lead to noncentrosymmetric (NCS) structures having desirable properties, such as piezoelectricity, pyroelectricity, and nonlinear optical activity $^{16}$. 
Direct fluorination of oxides with $\mathrm{F}_{2}(\mathrm{~g})$ or $\mathrm{HF}(\mathrm{g})$ is quite effective with minimal risk of side products. The handling of caustic, reactive gases, however, requires particularly specialized gas-phase reactors. In contrast, hydrothermal synthesis in hydrofluoric acid, or solutions of alkali fluorides, may be the easiest and safest route. The Teflon pouch approach is an efficient process to allow for fast development of discovery-based syntheses of new materials because various reactions can be performed in separate, small Teflon reaction pouches under identical, autogeneous conditions in an autoclave (Fig. 3c). Up to six reactions can be run in a $125 \mathrm{~mL}$ vessel.

Crystallographic long range ordering of oxide and fluoride anions has historically been a challenge, but materials based on anionic coordination polyhedra $\left[\mathrm{MO}_{m} \mathrm{~F}_{6-m}\right]^{n-}$ (where $(m, n)=(1$, 2) for $\mathrm{M}=\mathrm{V}^{5+}, \mathrm{Nb}^{5+}, \mathrm{Ta}^{5+},(2,2)$ for $\mathrm{M}=\mathrm{Mo}^{6+}, \mathrm{W}^{6+}$, and $(3,3)$ for $\mathrm{M}=\mathrm{Mo}^{6+}$ ) have been solvothermally prepared without apparent anion-site disorder (Fig. 3c) ${ }^{16}$. In the ordered perovskite $\mathrm{KNaNbOF}_{5}$ and $\mathrm{CsNaNbOF}_{5}$ (with the general formula $\mathrm{AM}^{\prime} \mathrm{MX}_{6}\left(\mathrm{M}^{\prime}=\right.$ alkali metal, $\mathrm{M}=2^{\text {nd }}$ order Jahn-Teller $d^{0}$ metal)), the interactions of the $\left[\mathrm{NbOF}_{5}\right]^{2-}$ anion with the combination of $\mathrm{Na} / \mathrm{K}$ or $\mathrm{Na} / \mathrm{Cs}$ differ significantly. The NCS structure $\left(\mathrm{KNaNbOF}_{5}\right)$ maintains a larger primary electronic distortion of the $\left[\mathrm{NbOF}_{5}\right]^{2-}$ anion along with a low coordination number of the $\mathrm{K}^{+}$ion, consistent with the largest bond strain index. In contrast, the $\mathrm{Cs}^{+}$ions of the centrosymmetric structure $\left.(\mathrm{CsNaNbOF})_{5}\right)$ can exhibit higher coordination numbers and the $\left[\mathrm{NbOF}_{5}\right]^{2-}$ anion exhibits a greatly reduced primary distortion. Theoretically, the group-theoretical method was applied to investigate anion ordering in the cubic perovskite, establishing 261 ordered low-symmetry structures, each with a unique spacegroup symmetry ${ }^{17}$. These idealized structures are considered as aristotypes with different derivatives formed by tilting of $\mathrm{MO}_{6}$ octahedra, providing a guide for designing NCS properties.

Thin film growth of oxides using pulsed laser deposition (PLD) or molecular beam epitaxy (MBE) is another useful bottom-up approach to construct desired artificial lattices, which has significantly contributed to the progress of condensed matter physics in the last two decades ${ }^{18}$. More rarely, thin film growth has been shown to be a promising method to prepare mixed-anion compounds, avoiding potential problems in anion diffusion. Oxynitrides films are fabricated by nitrogen plasma-assisted PLD, while polyvinylidene fluoride (PDVF) is used to topochemically convert oxide films to oxyfluoride ones. TaON films grown on a $\left(\mathrm{LaAlO}_{3}\right)_{0.3}\left(\mathrm{SrAl}_{0.5} \mathrm{Ta}_{0.5} \mathrm{O}_{3}\right)_{0.7}$ substrate adopt a metastable anatase structure with anion vacancies, leading to high-mobility electron transfer ${ }^{19}$. Tensile and compressive stresses from the substrate enables tailoring of the anion arrangement of a given structure. Compressively strained $\mathrm{SrTaO}_{2} \mathrm{~N}$ films show a partial cis-to-trans conversion of $\mathrm{TaO}_{4} \mathrm{~N}_{2}$ octahedra (Fig. 3c) ${ }^{20}$. An anion order/disorder transition can also be induced by strain engineering 21 . However, we note that there are still very few reports on mixed-anion films and most are thin film studies targeting optical (or surface) coating applications.

High pressure- and high-temperature conditions are typically used to stabilize dense materials through solid-state reactions or structural transformations. High-pressure reactions in sealed vessels prevent loss-of-volatile elements and so are particularly useful for anions, such as nitride to prevent loss-of-gaseous nitrogen (Fig. 3d). Autoclaves can be used for reactions under nitrogen up to kbar pressures, but many syntheses of oxynitrides have used direct reactions between solid oxides and nitrides (or oxynitrides) in multi-anvil presses where pressures can be extended to 10's of kbar (GPa) values. The spinel $\mathrm{Ga}_{3} \mathrm{O}_{3} \mathrm{~N}^{22}$ and $\mathrm{AZrO}_{2} \mathrm{~N}$ perovskites $(\mathrm{A}=\mathrm{Pr}, \mathrm{Nd} \text {, and } \mathrm{Sm})^{23}$ were synthesized by direct solid-state reaction between oxides and nitrides or oxynitrides under GPa pressures. The use of solid reagents (instead of
$\mathrm{NH}_{3}$ ) offers access to oxynitrides with middle-to-late transitions metals. A polar $\mathrm{LiNbO}_{3}$-type structure $\mathrm{MnTaO}_{2} \mathrm{~N}$ with a helical spin order was recently synthesized at $6 \mathrm{GPa}$ and $1400^{\circ} \mathrm{C}^{24}$. A non-polar analog $\mathrm{ZnTaO}_{2} \mathrm{~N}$ was also prepared ${ }^{25}$. New light atom materials have also been reported, such as the sphalerite-related boron oxynitride $\mathrm{B}_{6} \mathrm{~N}_{4} \mathrm{O}_{3}$ synthesized from direct reaction between $\mathrm{B}_{2} \mathrm{O}_{3}$ and hexagonal- $\mathrm{BN}$ at $15 \mathrm{GPa}$ and temperatures above $1900^{\circ} \mathrm{C}^{26}$. Pressurization of baddeleyite-structured TaON drives a transition to a cotunnite-type structure with a very highbulk modulus of $370 \mathrm{GPa}$ (Fig. $3 \mathrm{~d}$ ) ${ }^{27}$.

\section{Chemical and structural analyses}

Single crystal or powder diffraction methods are used to characterize many crystalline substances. A particular challenge for mixed-anion materials is to determine the distribution and degree of order-disorder of two or more anions. This complexity presents a challenge for both experiment and materials simulation (Fig. 3e), where equilibrium structures consisting of ordered or disordered anion configurations may be used for electronic structure calculations, e.g., those based on DFT or many-body methods. Ultimately to assess the properties of a mixed-anion material, the structure must be known. To that end, a number of structure-search algorithms, including cluster expansions ${ }^{28}$, special quasirandom structures ${ }^{29}$, and genetic algorithms ${ }^{30}$, frequently applied to multicomponent alloys and single-anion compounds, could be used to assess phase stability and solve structures in multi-anion compounds. In combination with experimental methods (below), a more complete description of the local and crystal structure can be obtained. These methods are also important for obtaining interaction energies for effective model Hamiltonians to describe ordering and ferroic transitions ${ }^{31}$.

Experimentally, the anion distribution may be studied directly using the scattering contrast between the anionic elements or indirectly through the different sizes or coordination environments of the anions in the structure. Direct X-ray scattering contrast is poor between elements from the same row of the periodic table, such as $\mathrm{N} / \mathrm{O} / \mathrm{F}$ or $\mathrm{As} / \mathrm{Se} / \mathrm{Br}$, and neutron scattering may be useful in some cases, for example, to differentiate $\mathrm{N}$ and $\mathrm{O}$ which have respective neutron scattering lengths of 9.36 and 5.83 $\mathrm{fm}$ (Table 1) in oxynitrides. Neutron scattering also enables the positions of these light atoms to be determined more precisely in the presence of heavy metal atoms than is usually possible from $\mathrm{X}$-ray refinements.

Anions that have very similar X-ray and neutron scattering factors, such as oxide and fluoride may be distinguished by their structural environments if well-ordered within a crystal structure. Differences in formal charge and size are captured by the popular bond valence sum (BVS) method $^{32}$, but even a simple approach based on apportioning ideal bond valences from Pauling's second crystal rule was found to account for anion orders in many oxyhalides and oxynitrides (Fig. $4 \mathrm{a})^{33}$. Increasing the formal anion charge tends to promote more covalent bonding to the metal cations and this can also enable anions to be distinguished; for example, vanadium forms very short 'vanadyl' bonds to oxide but not fluoride in $\mathrm{V}^{4+}$ and $\mathrm{V}^{5+}$ oxyfluorides.

Between the limits of fully ordered and randomly disordered anions, there are many cases of intermediate anion orders with local clustering or extended correlations that may give rise to non-random site occupancies in the averaged crystal structure. A particularly widespread example of such correlated disorder is found in $\mathrm{AMO}_{2} \mathrm{~N}$ and $\mathrm{AMON}_{2}$ perovskite oxynitrides where layers of zig-zag $\mathrm{MN}$ chains (Fig. 4c) result from strong-covalent interactions between high-valence transition metals $\mathrm{M}$ and nitride anions that promote local cis- $\mathrm{MN}_{2}\left(\right.$ or $\left.\mathrm{MO}_{4} \mathrm{~N}_{2}\right)$ configurations 

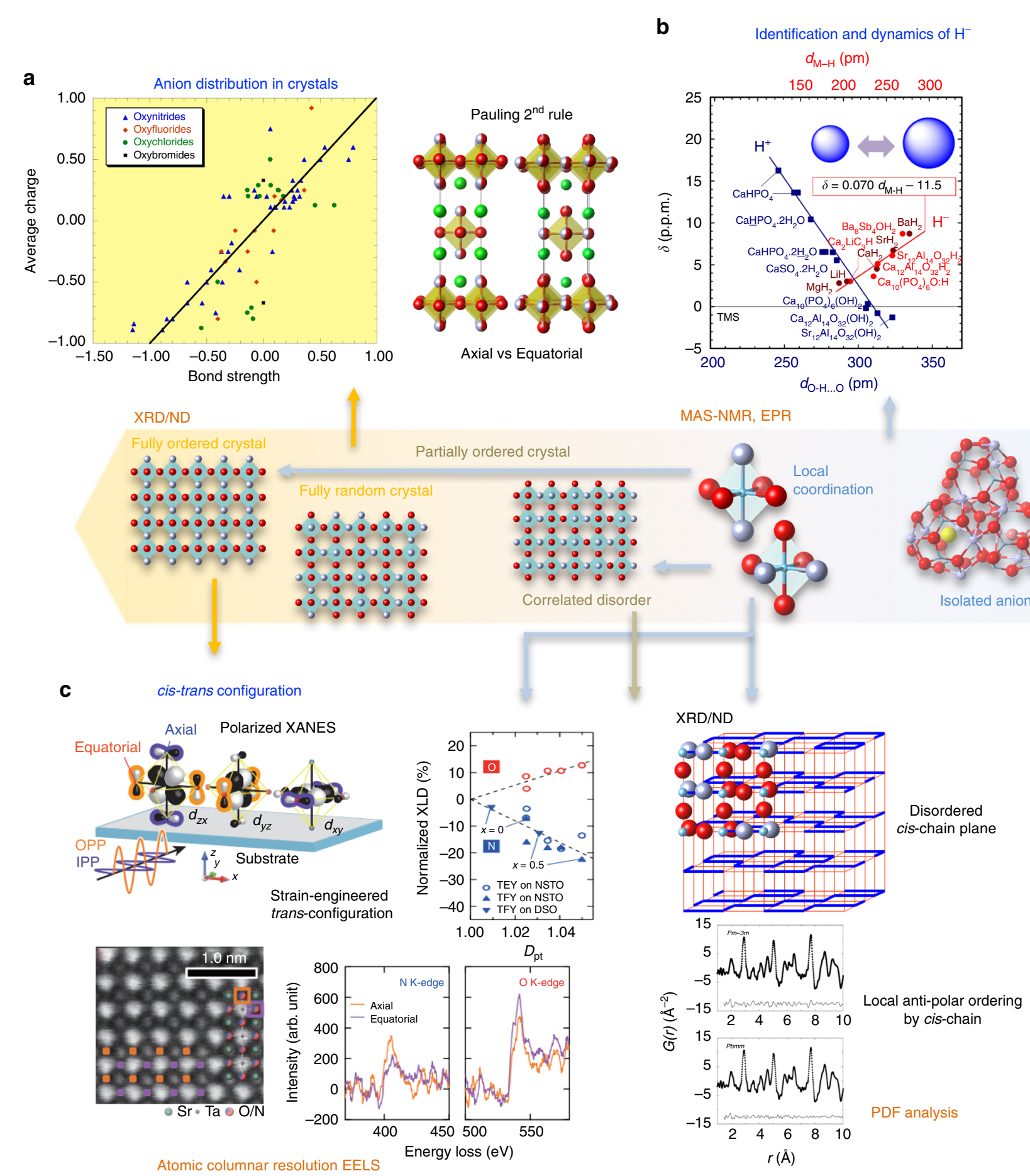

Fig. 4 Chemical and structural characterizations for mixed-anion compounds. Hierarchical representations from long-range ordered structures to correlated disordered states, and to local structures. a Prediction of anion distributions in mixed-anion ( $\mathrm{O}, \mathrm{N}, \mathrm{F}, \mathrm{Cl}$, and Br) crystals based on the Pauling's second rule: a correlation between the charge of an anion site with the calculated bond strength sums for the relevant site from $X$-ray diffraction (XRD) and neutron diffraction (ND) refinements ${ }^{33}$. For example, the apical site of the $\mathrm{Nb}(\mathrm{O}, \mathrm{F})_{6}$ octahedron in $\mathrm{K}_{2} \mathrm{NbO}_{3} \mathrm{~F}$ is favorably occupied by $\mathrm{F}^{-}$, while the equatorial site by $\mathrm{N}^{3-}$ in $\mathrm{Sr}_{2} \mathrm{TaO}_{3} \mathrm{~N}$. b Identification of $\mathrm{H}^{-}$using the correlation between the chemical shift $(\delta)$ of ${ }^{1} \mathrm{H}-\mathrm{NMR}$ and the $\mathrm{M}-\mathrm{H}$ distance $\left(d_{\mathrm{M}-\mathrm{H}}\right.$ ), where $\mathrm{M}$ is the neighboring cation (Fig. $2 \mathrm{a})^{44}$. An opposite dependence is seen for $\mathrm{OH}^{-}$. c Characterization of cis- and trans-coordination in $\mathrm{AMO}_{2} \mathrm{~N}$ perovskites (Fig. 1c). (Right) A tetragonal $\mathrm{SrTaO}_{2} \mathrm{~N}$ structure $(\mathrm{P} 4 / \mathrm{mmm}$ ) with the equatorial site occupied equally by $\mathrm{O} / \mathrm{N}$ and the apical site occupied completely by $\mathrm{O}$, giving disordered cis-chains, where thick/thin lines correspond to $\mathrm{M}-\mathrm{N}-\mathrm{M} / \mathrm{M}-\mathrm{O}-\mathrm{M}$ connections ${ }^{34}$. This model was deduced from the average site occupancies in $\mathbf{b}$. The correlated anion disorder in $\mathrm{AMON}_{2}$ perovskites is chemically symmetric through reversal of $\mathrm{O}$ and $\mathrm{N}$. PDF analysis of neutron total scattering data for $\mathrm{BaTaO}_{2} \mathrm{~N}$ reveals local O/N ordering originated from favorable cis-configuration of TaO $\mathrm{N}_{2}$ octahedra ${ }^{39}$. (Left) The trans-coordination in $\mathrm{SrTaO}_{2} \mathrm{~N}$ film under lateral compressive strain is probed by polarized XANES and STEM-EELS ${ }^{40}$. Some data are reproduced with permission from each journal 

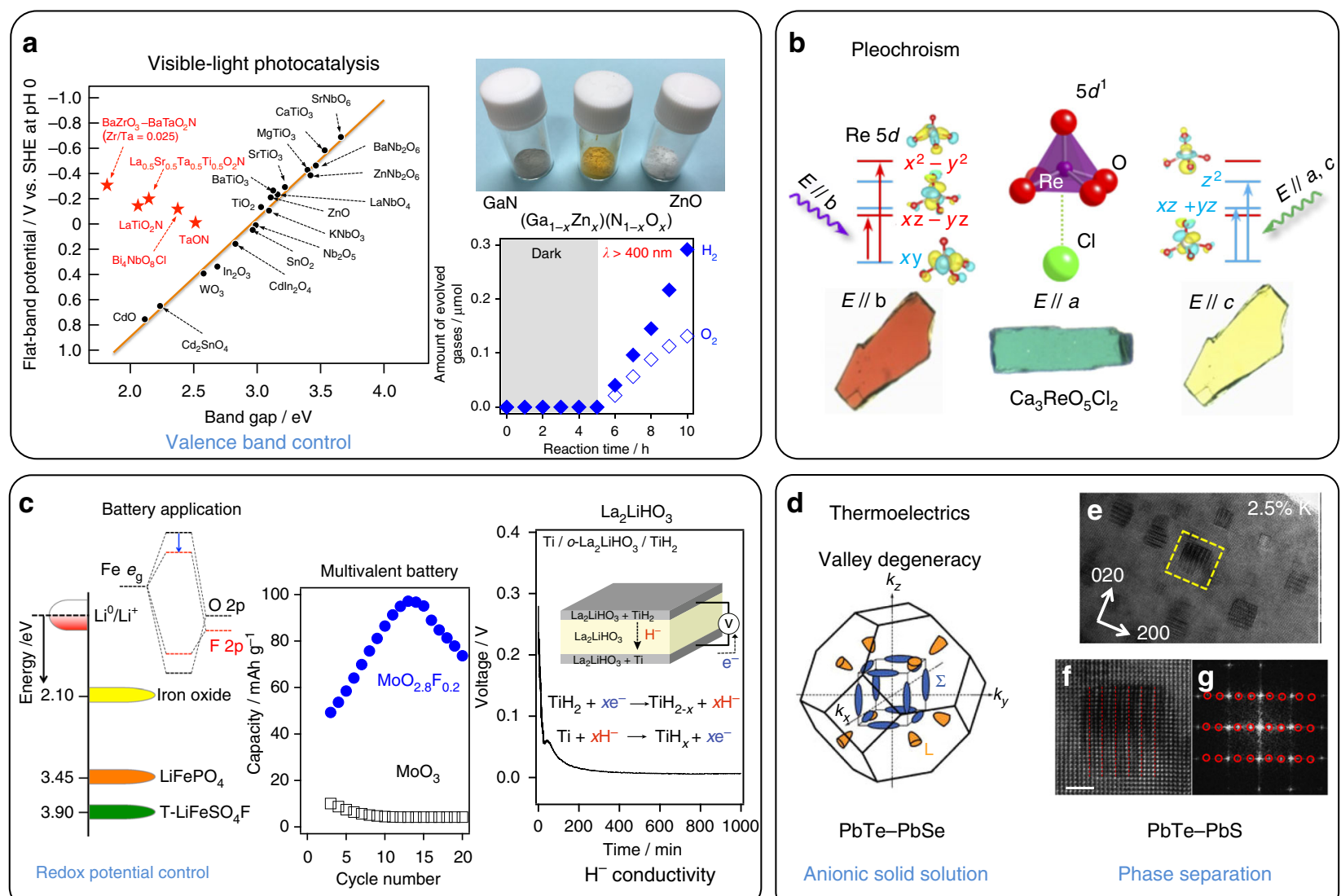

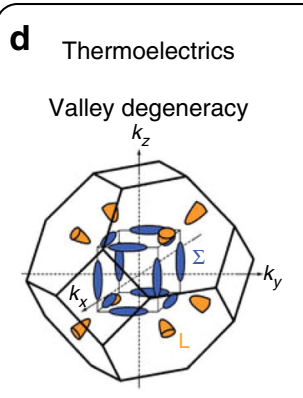

$\mathrm{PbTe}-\mathrm{PbSe}$

Anionic solid solution

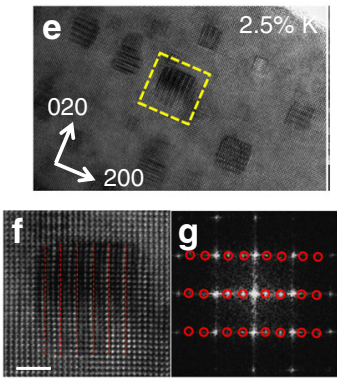

$\mathrm{PbTe}-\mathrm{PbS}$

Phase separation

Fig. 5 Mixed-anion driven chemical functions. a Visible-light photocatalysis (Fig. 1b). (Left) Flat-band potential as a function of the band gap, showing an empirical relation, $E_{\mathrm{FB}}(\mathrm{NHE}) \approx 2.94-E_{\mathrm{g}}$, for $d^{0}$ or $d^{10}$ oxide semiconductors ('Scaife plot'). ${ }^{51}$ (Right) Powders of $\mathrm{GaN}, \mathrm{ZnO}$ and their solid solution $\left(\mathrm{Ga}_{0.58} \mathrm{Zn}_{0.42}\right)\left(\mathrm{N}_{0.58} \mathrm{O}_{0.42}\right)$, and a time course data for overall water splitting under visible light using $\left(\mathrm{Ga}_{0.87} \mathrm{Zn}_{0.13}\right)\left(\mathrm{N}_{0.83} \mathrm{O}_{0.16}\right)$ with $\mathrm{RuO} \mathrm{O}_{2}$ nanoparticle cocatalyst ${ }^{59}$. b Pleochroism (Fig. 1a). $\mathrm{Ca}_{3} \mathrm{ReO}_{5} \mathrm{Cl}_{2}$ crystals showing different optical densities for incident light polarized along the $a, b$, and $c$ axes $^{68}$. c Battery applications. (Top left) Energy of the redox couples of iron phosphate frameworks relative to the Fermi level of metallic lithium (Fig. 1a, b) 72. (Bottom left) Capacity versus cycle number for $\mathrm{MoO}_{2.8} \mathrm{~F}_{0.2}$ over the first 18 cycles (Fig. 1b, e) ${ }^{76}$. (Right) A pure $\mathrm{H}^{-}$conductivity ${ }^{71}$. Discharge curve for a solid-state battery with the Ti/ $/ \mathrm{La}_{2} \mathrm{LiHO}_{3} / \mathrm{TiH}_{2}$ structure (Fig. 2a, b). d Thermoelectrics. (Left) Brillouin zone of $\mathrm{PbTe}_{1-x} \mathrm{Se}_{x}$, where the anion tuning allows creation of low-degeneracy hole pockets (orange) and the high-degeneracy hole pockets (blue) ${ }^{81}$. (Right) Microstructures for nanoscale precipitates of a phase-segregated (2.5\% K-doped) $\mathrm{PbTe}_{0.7} \mathrm{~S}_{0.3}{ }^{80}$. The lower panels show an enlarged image of cubic precipitates with the three-layered structure and its Fourier-transformed image. Some data shown here are reproduced with permission from each journal

(Fig. 1c, e). This order has been deduced from powder neutron refinements of $\mathrm{O} / \mathrm{N}$ site occupancies in materials, such as $\mathrm{SrMO}_{2} \mathrm{~N} \quad(\mathrm{M}=\mathrm{Nb}, \quad \mathrm{Ta})^{34}, \quad \mathrm{LaTaON}_{2}{ }^{35}, \quad$ and $\mathrm{AVO}_{2} \mathrm{~N}$ $(\mathrm{A}=\mathrm{Pr}, \mathrm{Nd})^{36,37}$ perovskites. Local $\mathrm{O} / \mathrm{N}$ correlations are also present in silicon oxynitrides where covalency tends to equalize the $\mathrm{SiO}_{4-n} \mathrm{~N}_{n}$ compositions of all nitridosilicate tetrahedra, for example, in melilite-type $\mathrm{Y}_{2} \mathrm{Si}_{3} \mathrm{O}_{3} \mathrm{~N}_{4}{ }^{38}$.

Analysis of total X-ray or neutron scattering data, including diffuse features from short-range correlations, as well as the Bragg scattering, has been used to construct the pair distribution function (PDF) of interatomic distances in many materials. Fitting of the PDF can be a powerful tool for revealing short range structural correlations in crystalline materials, as well as in amorphous substances ${ }^{39}$. Scattering or size contrast between anions can be used to determine their local order, for example, neutron PDF analysis revealed the prevalence of local cis- $\mathrm{TaN}_{2}$ configurations in the perovskite $\mathrm{BaTaO}_{2} \mathrm{~N}$ (Fig. $4 \mathrm{c}$ ) ${ }^{40}$.

Complementary information for analyzing the neutron- or $\mathrm{X}$ ray-PDFs can be acquired by other techniques, such as electron energy loss spectroscopy (EELS) combined with scanning transmission electron microscopy (STEM), X-ray absorption near edge structure (XANES) of X-ray absorption spectroscopy (Fig. 4c), and magic angle-spinning (MAS) nuclear magnetic resonance (NMR) (Fig. 4b), which provide not only anion composition but also the local structures. As opposed to the above diffraction methods that may have difficulty in distinguishing among $\mathrm{O}, \mathrm{F}$, and $\mathrm{N}$, state-of-the-art STEM-EELS can determine atomic occupancy with a resolution of each atomic column in a crystal lattice. This is particularly advantageous for thin film samples, in which crystal orientation is well controlled but precise structural analysis by diffraction methods is not as applicable. XANES is also effective for identifying the above elements and determining their chemical states. Perovskite $\left(\mathrm{Ca}_{1-x} \mathrm{Sr}_{x}\right) \mathrm{TaO}_{2} \mathrm{~N}$ epitaxial films with controlled strains were analyzed using XANES with a polarized light source ${ }^{41}$. From the intensity of $\pi$-bonded states of $\mathrm{O}$ or $\mathrm{N}$ with $\mathrm{Ta}-5 d$ via excitation from $\mathrm{O}$ and $\mathrm{N}$ core levels, it was concluded that $\mathrm{N}$ preferably takes the trans configuration in the $\mathrm{TaO}_{4} \mathrm{~N}_{2}$ octahedron for compressive strain states, which was also supported by STEM-EELS and DFT calculations (Fig. 4c).

NMR has also been effective for (local) structural determination of mixed-anion compounds ${ }^{42}$. Structural determination of industrially important $\mathrm{Si}-\mathrm{Al}-\mathrm{O}-\mathrm{N}$ materials (SiAlON), which are 
solid solutions between $\mathrm{Si}_{3} \mathrm{~N}_{4}$ and $\mathrm{Al}_{2} \mathrm{O}_{3}$, by X-ray diffractometry is insufficient because X-ray scattering factors within the $\mathrm{Si}-\mathrm{Al}$ and $\mathrm{O}-\mathrm{N}$ pairs are similar; however, the high-resolution MASNMR method overcomes this challenge. Local coordination around the ${ }^{29} \mathrm{Si}$ and ${ }^{27} \mathrm{Al}$ nuclei was determined by MAS-NMR and their integration gives a full structural model for such oxynitride materials ${ }^{43}$ and, coupled with ab initio calculations, preferential $\mathrm{Al}-\mathrm{O}$ clustering ${ }^{44}$.

High sensitivity is a hallmark of ${ }^{1} \mathrm{H}-\mathrm{NMR}$, enabling detection of $\mathrm{H}^{-}$with a concentration as low as $0.1 \%$ of the total anions. Coexistence of $\mathrm{H}^{+}\left(\right.$or $\mathrm{OH}^{-}$) and $\mathrm{H}^{-}$ions in a single material is not trivial because their thermodynamic stability is different and depends on oxygen partial pressure, $p\left(\mathrm{O}_{2}\right)$. However, these two species sometimes coexist due to non-equilibrium ${ }^{14}$ or hightemperature equilibrium ${ }^{45}$. Recent ${ }^{1} \mathrm{H}$-NMR has identified a 'hidden' hydride anion and its local environment in hydroxyloxides like apatite $\mathrm{Ca}_{10}\left(\mathrm{PO}_{4}\right)_{6}(\mathrm{OH})_{2}{ }^{45}$. Here, the size flexibility of $\mathrm{H}^{-}$(Fig. 2a) substantially changes the electron density (and relevant magnetic field shielding) at ${ }^{1} \mathrm{H}$ nuclei and hence the isotropic chemical shift of ${ }^{1} \mathrm{H}$-NMR (Fig. $4 \mathrm{~b}$ ).

Cage structures can incorporate various anionic species. Mayenite $12 \mathrm{CaO} \cdot 7 \mathrm{Al}_{2} \mathrm{O}_{3}$ with a positively charged cage structure is shown to host many mono- or divalent guest anions $\left(\mathrm{F}^{-}, \mathrm{Cl}^{-}\right.$, $\mathrm{S}^{2-}, \mathrm{O}^{-}, \mathrm{O}_{2}^{-}, \mathrm{O}_{2}{ }^{2-}, \mathrm{C}_{2}{ }^{2-}, \mathrm{NH}^{2-}, \mathrm{CN}^{-}, \mathrm{O}^{2-}, \mathrm{OH}^{-}$, and $\left.\mathrm{H}^{-}\right)$ (Fig. 1h) ${ }^{46}$. Raman and electron paramagnetic spin resonance (EPR) measurements show that active oxygen species of $\mathrm{O}^{-}, \mathrm{O}_{2}^{-}$, and $\mathrm{O}_{2}{ }^{2-}$, less stable than $\mathrm{O}^{2-}$ in oxide crystals and usually formed on surfaces transiently ${ }^{47}$, can stably exist in the cage. In a lightly hydride-doped mayenite, an irradiation of UV light induces a chemical reaction in the cage: $\mathrm{H}^{-}+\mathrm{O}^{2-} \Leftrightarrow 2 \mathrm{e}^{-}+\mathrm{OH}^{-}$ (Fig. 2d). Here, the $\mathrm{e}^{-}$is confined within the cage, like $F^{+}$centers in alkali halides, and is responsible for a 'permanent' electrical conductivity as the reverse of the above reaction proceeds with a timescale of 10,000 years at room temperature ${ }^{48}$. Formation of transient atomic hydrogen during the photo-dissociation of $\mathrm{H}^{-}$is monitored by EPR, revealing that its lifetime of the atomic hydrogen is a few minutes at $40 \mathrm{~K}^{49}$.

\section{Chemical properties}

Optical applications. Many oxides have a wide band gap and so are transparent. Valence band engineering according to Fig. $1 \mathrm{~b}$ is useful to make them responsive to visible light, the main component of solar spectrum. When the oxide anion is substituted by other anions with less electronegativity like nitride (Table 1 ), the non-oxide $p$ orbitals having high-potential energy extend the valence band and allow for visible-light absorption. Solid solutions of $\mathrm{CaTaO}_{2} \mathrm{~N}$ and $\mathrm{LaTaON}_{2}$ perovskites have tuneable colors that range from yellow to red via orange $(500-600 \mathrm{~nm}$ in wavelengths), depending on the composition of the solid solutions ${ }^{50}$. These oxynitrides are potential non-toxic alternatives to chalcogenide-based inorganic pigments.

This strategy may be of particular importance for finding a photocatalyst which can split water to produce $\mathrm{H}_{2}$ and $\mathrm{O}_{2}$ under visible light. Otherwise, if oxides with a small band gap of $<3 \mathrm{eV}$ (corresponding to $\lambda>400 \mathrm{~nm}$ ) are used, the conduction band minimum (CBM, or flat-band potential) becomes more positive than the water reduction potential $(0 \mathrm{~V}$ vs. NHE (normal hydrogen electrode) at $\mathrm{pH}$ 0), a limitation shown by Scaife ${ }^{50}$ (Fig. 5a). So far, various oxynitrides and oxysulfides that overcome this limitation have shown water splitting performance ${ }^{52-54}$. Some of them (e.g., $\mathrm{ZrO}_{2}$-grafted $\mathrm{TaON}$ ) were found to be a useful component for Z-scheme type water splitting ${ }^{55}$ and $\mathrm{CO}_{2}$ reduction with the aid of a functional metal complex ${ }^{56}$.

Unexpected changes in electronic structure are often found in mixed-anion compounds, which presents a challenge to predictive materials theory. Methods based on DFT require appropriate exchange-correlation functionals ${ }^{57,58}$ to accurately describe the mixed bonding character presented in these materials. Alloying wide-gap semiconductors, $\mathrm{GaN}$ and $\mathrm{ZnO}$, results in an unprecedented yellowish powder (Fig. 5a), and this provides the first reproducible example of visible-light-driven overall water splitting ${ }^{59}$. Loaded with nanoparticulate $\mathrm{Rh}_{2} \mathrm{O}_{3}-\mathrm{Cr}_{2} \mathrm{O}_{3}$ that works as an active site for $\mathrm{H}_{2}$ evolution, $\left(\mathrm{Ga}_{1-x} \mathrm{Zn}_{x}\right)\left(\mathrm{N}_{1-x} \mathrm{O}_{x}\right)$ exhibited $\mathrm{H}_{2}$ and $\mathrm{O}_{2}$ evolution for $>3$ months ${ }^{60}$. One of the drawbacks of mixed anion photocatalysts in general is their instability against photo-induced holes. This is seen even in $\left(\mathrm{Ga}_{1-x} \mathrm{Zn}_{x}\right)\left(\mathrm{N}_{1-x} \mathrm{O}_{x}\right)$, where the photoinduced holes oxidize the $\mathrm{N}^{3-}$ anion, degrading its photocatalytic activity by self-decomposition ${ }^{60}$. $\mathrm{Bi}_{4} \mathrm{NbO}_{8} \mathrm{Cl}$, a Sillen-Aurivillius layered perovskite, was recently shown to stably oxidize water without any surface modifications. The observed stability is attributed to highly dispersive $\mathrm{O}-2 p$ orbitals (dominating the VBM instead of $(-3 p)^{61}$. A recent study on a series of layered bismuth oxyhalides has revealed that Madelung site potentials of anions capture essential features of the valence band structures of these materials, enabling prediction and design of the valence band structures by manipulating the stacking sequence of layers $\left(\right.$ Fig. 1g) ${ }^{62}$.

Oxynitrides doped with rare earth elements show photoluminescence. Here, substitution of $\mathrm{O}^{2-}$ for $\mathrm{N}^{3-}$ gives a greater CFS of the $5 d$ levels of rare earth elements, such as $\mathrm{Eu}^{2+}$ (Fig. 1a), extending the excitation and emission peaks to longer wavelengths. SiAlON, $\left(\mathrm{Si}_{3-x} \mathrm{Al}_{x}\right)\left(\mathrm{N}_{4-x} \mathrm{O}_{x}\right): \mathrm{Eu}^{2+}$, and related phosphors undergo photoexcitation by absorbing blue light, and emitting yellow light, and hence are used in phosphor-converted whitelight emitting LED lamps (WLEDs) ${ }^{63}$. Other important SiAlONrelated phosphors used in WLEDs are the $\mathrm{ASi}_{2} \mathrm{O}_{2} \mathrm{~N}_{2}: \mathrm{Eu}^{2+}$ and $\mathrm{A}_{2} \mathrm{Si}_{5} \mathrm{~N}_{8}: \mathrm{Eu}^{2+}$ families $(\mathrm{A}=\mathrm{Ca}, \mathrm{Sr} \text {, and } \mathrm{Ba})^{64}$, the latter can be oxide-doped with $\mathrm{Al}^{3+}$ providing charge compensation in $\mathrm{A}_{2} \mathrm{Si}_{5}$ ${ }_{-x} \mathrm{Al}_{x} \mathrm{~N}_{8-x} \mathrm{O}_{x}: \mathrm{Eu}^{2+}(x=0-1)^{65}$. The high thermal and chemical stability arising from covalent $\mathrm{M}-\mathrm{N}$ bonding (Fig. 1e) leads to practical applications. Similar chemical tuning has been applied for oxyfluoride type solid solutions, such as $\mathrm{A}^{\mathrm{II}}{ }_{3-}$ ${ }_{x} \mathrm{~A}^{\mathrm{III}} \mathrm{MO}_{4} \mathrm{~F}$ family with $\mathrm{A}=\mathrm{Sr}, \mathrm{Ca}, \mathrm{Ba}$ and $\mathrm{M}=\mathrm{Al}$, Ga (e.g., $\left.(\mathrm{Sr}, \mathrm{Ba})_{2.975} \mathrm{Ce}_{0.025} \mathrm{AlO}_{4} \mathrm{~F}\right){ }^{66,67}$.

Another interesting feature from the mixed-anion system is pleochroism, recently found in $\mathrm{Ca}_{3} \mathrm{ReO}_{5} \mathrm{Cl}_{2}$ with the $\mathrm{Re}^{6+}$ ion in a $5 d^{1}$ configuration (Fig. 5b) ${ }^{68}$. The heavily distorted octahedral coordination of $\mathrm{Re}^{6+}$ by one $\mathrm{Cl}^{-}$and five $\mathrm{O}^{2-}$ anions along with the spatially extended $5 d$ orbitals gives rise to unique CFS energy levels (Fig. 1a), much greater than for $3 d$ orbitals owing to stronger electrostatic interactions exerted from the ligands. The uni-directional alignment of these octahedra along the $c$-axis makes the $d-d$ transitions highly anisotropic. As a result, this compound exhibits very different colors depending on the viewing direction, i.e., distinct pleochroism.

Anion conductors. Certain anions are mobile in solids. The merit of a mixed-anion material is that it allows for anion diffusion by one (more ionic, less highly charged) anion and structural stability by the other (more covalent, more highly charged) anion (Fig. 1e, f). This concept can be directly assessed using electronic structure methods, where calculations of intrinsic defect levels and diffusion barriers ${ }^{69}$ can be correlated with changes in the anion lattice. A layered lanthanum oxychloride $\mathrm{LaOCl}$ is a $\mathrm{Cl}$-ion conductor ${ }^{70}$. While $\mathrm{La}_{2} \mathrm{O}_{3}$ and $\mathrm{LaCl}_{3}$ are both sensitive to moisture, a critical disadvantage for practical applications, $\mathrm{LaOCl}$ is water-insoluble and exhibits $\mathrm{Cl}$ conductivity. An aliovalent $\mathrm{Ca}-$ for-La substitution generates vacancies at the chloride site and hence the $\mathrm{Cl}^{-}$conductivity is improved. 

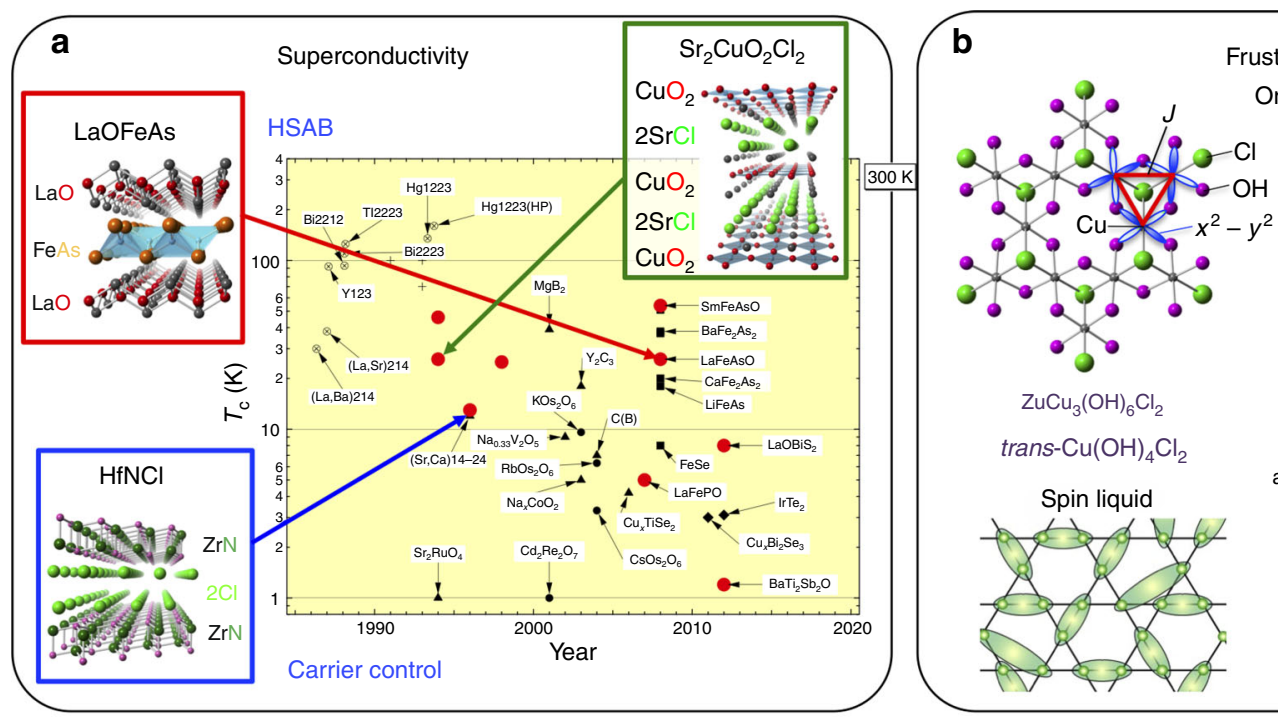

Orbitrated magnetism

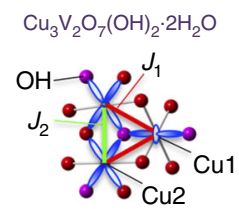

$\mathrm{BaCu}_{3} \mathrm{~V}_{2} \mathrm{O}_{8}(\mathrm{OH})_{2}$ trans- $\mathrm{Cu}(\mathrm{OH})_{4} \mathrm{Cl}_{2}$

Spin liquid
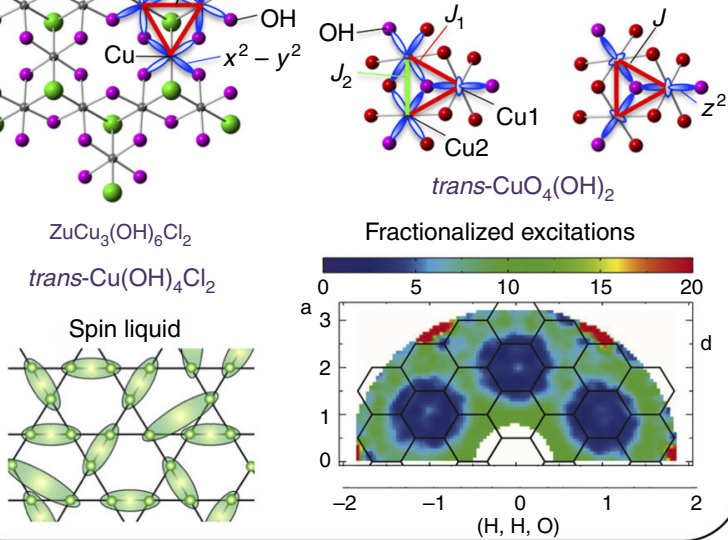

trans- $\mathrm{CuO}_{4}(\mathrm{OH})_{2}$

Fractionalized excitations
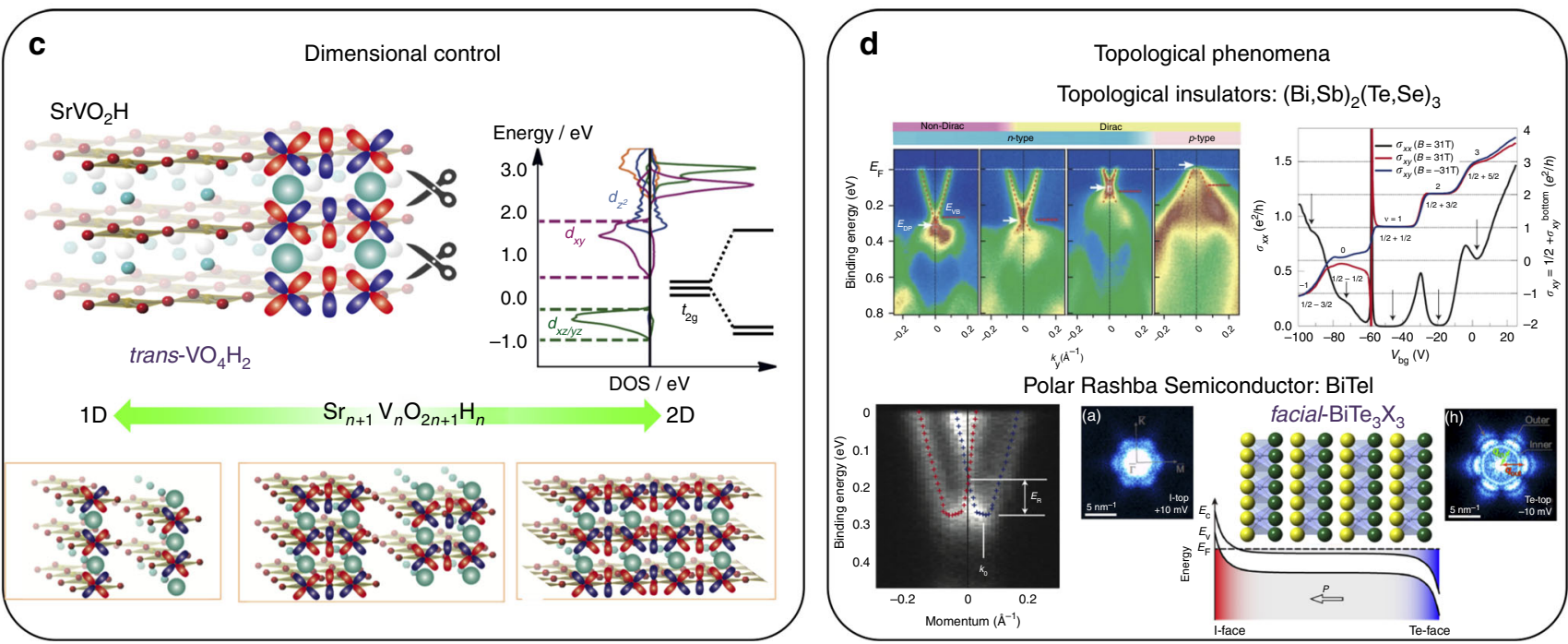

Fig. 6 Mixed-anion driven physical functions. a Superconducting transition temperatures as a function of the year of discovery, where symbols of mixedanion compounds are highlighted in color. Layered structures of parent high- $\mathrm{T}_{\mathrm{c}}$ superconductors $\mathrm{HfNCl}^{83}, \mathrm{LaOFeAs}^{104}$ and $\mathrm{Sr}_{2} \mathrm{CuO}_{2} \mathrm{Cl}_{2}^{89}$ are shown (Fig. 1g). b (Top) Geometrical frustration in $\mathrm{ZnCu}_{3}(\mathrm{OH})_{6} \mathrm{Cl}_{2}, \mathrm{Cu}_{3} \mathrm{~V}_{2} \mathrm{O}_{7}(\mathrm{OH})_{2} \cdot 2 \mathrm{H}_{2} \mathrm{O}$ and $\mathrm{BaCu}_{3} \mathrm{~V}_{2} \mathrm{O}_{8}(\mathrm{OH})_{2}$ with the $\mathrm{S}=1 / 2 \mathrm{kagomé} \mathrm{lattice} 85,87$. A Cutriangle unit is formed by the chlorine anion of three trans- $\mathrm{Cu}(\mathrm{OH})_{4} \mathrm{Cl}_{2}$ octahedra in the former, while sharing the $\mathrm{OH}$ anion of three trans- $\mathrm{CuO} \mathrm{O}_{4}(\mathrm{OH})_{2}$ octahedra in the latter two compounds. Different orbital-ordering patterns appear in these compounds, leading to various exotic quantum states. (Bottom) A spin liquid ground state and inelastic neutron scattering on $\mathrm{ZnCu}_{3}(\mathrm{OH})_{6} \mathrm{Cl}_{2}$ showing fractionalized excitations ${ }^{86}$. c (Upper) $\mathrm{Crystal}$ and electronic structures of $\mathrm{SrV}^{\mathrm{III}} \mathrm{O}_{2} \mathrm{H}$ with trans- $\mathrm{VO}_{4} \mathrm{H}_{2}$ octahedra ${ }^{9} . \mathrm{H}^{-}$1s orbitals, orthogonal with $\mathrm{V} t_{2 \mathrm{~g}}$ orbitals act as orbital scissors (or $\pi$-blockers), resulting in $2 \mathrm{D}$ electronic structures (Fig. 2c). (Lower) 2D-to-1D crossover in serial $n$-legged spin ladders, $\mathrm{Sr}_{n+1} \mathrm{~V}_{n} \mathrm{O}_{2 n+1} \mathrm{H}_{n}$ (Fig. $1 \mathrm{~g}$ ) $90 . \mathbf{d}$ (Upper left) Band dispersions of the cation/anion co-substituted $(\mathrm{Bi}, \mathrm{Sb})_{2}(\mathrm{Te}, \mathrm{Se})_{3}$ with a tunable Dirac cone ${ }^{91}$. (Upper right) Topological surface state quantum Hall effect in the intrinsic topological insulator $(\mathrm{Bi}, \mathrm{Sb})_{2}(\mathrm{Te}, \mathrm{Se})_{3}{ }^{92}$. (Lower left) Giant bulk Rashba effect in BiTel with polar facial-BiTe $\mathrm{l}_{3}$ octahedral layers (Fig. $1 \mathrm{~d}$ ) ${ }^{93}$. (Lower right) Spectroscopic imaging scanning tunneling microscopy of BiTel evidencing the ambipolar $2 \mathrm{D}$ carriers at the surface, indicating the formation of lateral $p-n$ junctions $^{94}$. Some data shown here are reproduced with permission from each journal

$\mathrm{H}^{-}$anion conductors are expected to provide high-energy storage and conversion devices because $\mathrm{H}^{-}$has an appropriate ionic size for fast diffusion (Fig. 2a), a low electronegativity (Fig. 2b) and a high-standard redox potential of $\mathrm{H}^{-} / \mathrm{H}_{2}(-2.3 \mathrm{~V})$, close to that of $\mathrm{Mg} / \mathrm{Mg}^{2+}(-2.4 \mathrm{~V})$. A pure $\mathrm{H}^{-}$conduction in $\mathrm{K}_{2} \mathrm{NiF}_{4}$-type $\mathrm{La}_{2} \mathrm{LiHO}_{3}$ has recently been demonstrated, using an all-solid-state $\mathrm{TiH}_{2} / \mathrm{La}_{2} \mathrm{LiHO}_{3} / \mathrm{Ti}$ cell (Fig. $\left.5 \mathrm{c}\right)^{71}$. The twodimensional (2D) $\mathrm{H}^{-}$diffusion is further facilitated by introducing $\mathrm{H}^{-}$vacancies, leading to the activation energy of $68.4 \mathrm{~kJ} \mathrm{~mol}^{-1}$ for $\mathrm{La}_{0.6} \mathrm{Sr}_{1.4} \mathrm{LiH}_{1.6} \mathrm{O}_{2}$.

Battery electrodes. Mixed-anion chemistry of oxyfluorides offers a new handle to tune the redox potential of battery electrodes.
Here, instead of 'direct' valence (anion) band control described in Fig. 1b, anion substitution enables an 'indirect' manipulation of the cation band. The redox potential of the $\mathrm{LiFeSO}_{4} \mathrm{~F}$ phase (tavorite) is higher than the $\mathrm{LiFePO}_{4}$ phase (olivine) by $750 \mathrm{mV}^{72}$. This primarily results from the weaker (more ionic) $\mathrm{Fe}-\mathrm{F}$ bond as compared with the Fe-O bond (Fig. 1e), which stabilizes the antibonding band of $\mathrm{Fe} e_{\mathrm{g}}$ orbitals (Fig. 5c). Furthermore, $\mathrm{Ag}_{2} \mathrm{~V}_{2} \mathrm{O}_{6} \mathrm{~F}_{2}$ (SVOF) is a battery material potentially used in cardiac defibrillators owing to a fast discharge rate and high-current density $^{73}$. The silver density in SVOF is greater than that of the currently used industry standard cathode material $\mathrm{Ag}_{2} \mathrm{~V}_{4} \mathrm{O}_{11}$ $(\mathrm{SVO})^{74}$ and thus the current density above $3 \mathrm{~V}$ for SVOF (148 $\mathrm{mAh} / \mathrm{g})$ is greater than that for SVO $(100 \mathrm{mAh} / \mathrm{g})$. The current 
density above $3 \mathrm{~V}$ is sufficient and the potential at which it is delivered $(3.52 \mathrm{~V})$ is $300 \mathrm{mV}$ greater than SVO owing to the fluoride incorporation (Fig. 1b).

Multivalent batteries exhibit a number of potentially valuable advantages compared to current lithium technology. The first functional multivalent battery was constructed in 2000; this prototype used a magnesium metal anode against a low-voltage Chevrel phase cathode ${ }^{75}$. A significant barrier to the adoption of magnesium batteries is the lack of an available high-voltage cathode that can reversibly intercalate magnesium. Cathodes composed of layered molybdenum fluoro-bronze are found to reversibly intercalate magnesium ${ }^{76} . \mathrm{MoO}_{2.8} \mathrm{~F}_{0.2}$, combined with a $\mathrm{Mg}$-based electrolyte, gave a reversible capacity of nearly $80 \mathrm{mAh} /$ $\mathrm{g}$, an order of magnitude higher than isostructural $\alpha-\mathrm{MoO}_{3}$ with a similar particle size (Fig. 5c). First-principles calculations revealed that the incorporation of fluoride within the crystal lattice reduces nearby molybdenum ions, enhancing in-plane electronic conductivity ${ }^{77}$. The associated increase in electronic screening reduces the activation barrier for $\mathrm{Mg}$ ion diffusion but yet does not significantly lower the voltage.

Thermoelectric materials. Thermoelectric materials enable direct conversion between thermal and electrical energy. Optimal materials with a high figure of merit ZT have a high Seebeck coefficient and electronic conductivity in combination with a lowthermal conductivity. $\mathrm{BiCuSeO}$ with $\left(\mathrm{Cu}_{2} \mathrm{Se}_{2}\right)^{2-}$ layers alternately stacked with $\left(\mathrm{Bi}_{2} \mathrm{O}_{2}\right)^{2+}$ layers (Fig. $1 \mathrm{~g}$ ), is a promising thermoelectric material, where one layer is responsible for electric conduction, while another lowers thermal conductivity ${ }^{78}$.

Nanostructuring which may be based on local segregation of anions is another effective means to reduce phonon thermal conductivity. The $\mathrm{PbTe}-\mathrm{PbS}$ system exhibits phase separation (spinodal decomposition), owing to a large difference in the anion sizes (Hume-Rothery rules) ${ }^{79}$. The resultant $\mathrm{PbTe}$-rich and PbSrich regions form dissimilar nanostructures with interphase boundaries that act as effective scattering centers for shortwavelength phonons (Fig. 5d). A nominal composition of $\mathrm{PbTe}_{0.7} \mathrm{~S}_{0.3}$ doped with $2.5 \% \mathrm{~K}$ achieved a figure-of-merit $\mathrm{ZT}$ of $>2$ over a wide temperature range from 400 to $650{ }^{\circ} \mathrm{C}^{80}$. On contrary, a complete solid solution is formed in the $\mathrm{PbTe}-\mathrm{PbSe}$ system. By tuning the anionic composition in $\mathrm{Pb}\left(\mathrm{Te}_{1-x} \mathrm{Se}_{x}\right)$, the electronic band structure exhibits high-valley degeneracy (Fig. 5d), leading to an optimized $\mathrm{ZT}$ value of 1.8 at $577^{\circ} \mathrm{C}^{81}$.

\section{Physical properties}

Ordering of two anions within a material often leads to low dimensionality in structural and physical properties. Layering of different anion types (Fig. $1 \mathrm{~g}$ ) is common and leads to $2 \mathrm{D}$ conductivity or magnetic correlations when cations with unpaired electrons are present. The $\mathrm{ZrCuSiAs}$ structure type is a flexible arrangement that allows two different anions and cations to segregate into distinct layers according to HSAB (hard and soft acids and bases) principles. Many mixed-anion materials adopt the $\mathrm{ZrCuSiAs}$ type, notably the $\mathrm{LnFeAsO}$ family of layered magnetic conductors and (when suitably doped) high- $T_{c}$ superconductors (Fig. 6a), the p-type semiconductor LaCuSO, the ferromagnetic Kondo material CeRuPO, and the Ag-ion conductor LaAgSO ${ }^{82}$. Layered order of nitride and halide anions in MNX materials $(\mathrm{M}=\mathrm{Ti}, \mathrm{Zr}$, and $\mathrm{Hf} ; \mathrm{X}=\mathrm{Cl}, \mathrm{Br}$, and $\mathrm{I})$ results in $\mathrm{X}-\mathrm{M}-\mathrm{N}-\mathrm{N}-\mathrm{M}-\mathrm{X}$ slabs separated by van der Waals gaps (Fig. 6a) into which cations such as lithium are intercalated, leading to conductivity and superconductivity ${ }^{83}$.

Multiple anions and their ratios may be used to control dimensionality and connectivity of magnetic interactions. $\mathrm{V}^{4+}$ and $\mathrm{Cu}^{2+}$ both have spin $S=1 / 2$ and so are of interest for quantum magnetic and superconducting properties, especially in low-dimensional structures that are often found in mixed-anion materials. In the early copper oxide superconductor studies, two copper oxyhalides, $\mathrm{Sr}_{2} \mathrm{CuO}_{2} \mathrm{~F}_{2+\delta}{ }^{84}$ and $(\mathrm{Ca}, \mathrm{Na})_{2} \mathrm{CuO}_{2} \mathrm{Cl}_{2}{ }^{85}$, played a role in understanding the superconducting mechanism (Fig. 6a). Although, these compounds possess $\mathrm{F}^{-}$and $\mathrm{Cl}^{-}$ions instead of $\mathrm{O}^{2-}$ ions at the apical site above and below the $\mathrm{Cu}^{2+}$ ions, they are superconducting with $T_{c}=46$ and $26 \mathrm{~K}$, respectively. This fact challenged the theoretical models proposing a vital role of the apical oxygen in the superconducting mechanism. Now it is well established that the high- $T_{c}$ superconductivity occurs within the $\mathrm{CuO}_{2}$ sheet having a strong covalency between the $\mathrm{Cu} d_{x^{2}-y^{2}}$ and $\mathrm{O} 2 p_{\sigma}$ states, while the apical-site anions (oxide ions) are more ionic (Fig. 1e), resulting in the $2 \mathrm{D}$ electronic state. In $\mathrm{V}^{4+}$ oxyfluorides, the $\mathrm{V}=\mathrm{O}$ vanadyl oxide anions do not link to other cations whereas fluorides readily form $\mathrm{V}-\mathrm{F}-\mathrm{V}$ bridges, enabling many structural topologies to be achieved. DQVOF (Diammonium Quinuclidinium Vanadium OxyFluoride; $\left.\left[\mathrm{NH}_{4}\right]_{2}\left[\mathrm{C}_{7} \mathrm{H}_{14} \mathrm{~N}\right]\left[\mathrm{V}_{7} \mathrm{O}_{6} \mathrm{~F}_{18}\right]\right)$ is notable as a geometrically frustrated kagomé bilayer material with a gapless spin liquid ground state, instead of the conventional Néel order (Fig. 6b) ${ }^{86}$. Various synthetic copper minerals with $\mathrm{Cu}^{2+}(S=1 / 2$ ion) and mixed anions have been studied as geometrically frustrated quantum magnets that can also show exotic ground states. A good example is herbertsmithite, $\mathrm{ZnCu}_{3}(\mathrm{OH})_{6} \mathrm{Cl}_{2}$ (Fig. 6b), in which the $\mathrm{Cu}^{2+}$ ion is coordinated by two axial $\mathrm{Cl}^{-}$ions and four equatorial $\mathrm{OH}^{-}$ ions with its spin residing on the $d_{x^{2}-y^{2}}$ orbital ${ }^{87}$. The $\mathrm{Cu}^{2+}$ spins form a 2D kagomé lattice and are coupled to each other by strong superexchange interactions only via the $\mathrm{OH}^{-}$ions. The compound exhibits no long-range order down to $50 \mathrm{mK}$ with fractionalized excitations (Fig. $6 \mathrm{~b})^{88}$, owing to the strong frustration on the kagomé lattice. Volborthite $\mathrm{Cu}_{3} \mathrm{~V}_{2} \mathrm{O}_{7}(\mathrm{OH})_{2} \cdot 2 \mathrm{H}_{2} \mathrm{O}$ and vesignieite $\mathrm{BaCu}_{3} \mathrm{~V}_{2} \mathrm{O}_{8}(\mathrm{OH})_{2}$ with trans- $\mathrm{CuO}_{4}(\mathrm{OH})_{2}$ octahedra having different orbital arrangements composed of $d_{x^{2}-y^{2}} / d_{z^{2}}$ and $d_{z^{2}}$ orbitals, respectively, enrich the phase diagram of the kagomé antiferromagnet ${ }^{89}$.

The lack of $p$ orbitals in the valence shell of $\mathrm{H}^{-}(1 s)$ effectively blocks the $\pi$-symmetry exchange pathways (Fig. 2c), a situation occurring in $\mathrm{SrV}^{\mathrm{III}} \mathrm{O}_{2} \mathrm{H}$ with $\left(t_{2 \mathrm{~g}}\right)^{2}$, where the in-plane exchange via $\mathrm{V}_{\mathrm{d} \pi}-\mathrm{O}_{\mathrm{p} \pi}-\mathrm{V}_{\mathrm{d} \pi}$ is much greater than the out-of-plane one via $\mathrm{V}_{\mathrm{d} \pi}-\mathrm{H}_{1 \mathrm{~s}}-\mathrm{V}_{\mathrm{d} \pi}$ interactions (Fig. $\left.6 \mathrm{c}\right)^{9}$. The application of pressure to the Mott insulator drives a transition to a metal at $\sim 50 \mathrm{GPa}$. Interestingly, despite the enormous compressibility of hydride (Fig. 2a), which is twice as compressible as oxide (Fig. 2a), the electronic structure of the metallic phase is quasi$2 \mathrm{D}$, meaning that the hydride ligand acts as a ' $\pi$-blocker'. The dimensional control from $2 \mathrm{D}$ to $1 \mathrm{D}$ is possible in the $n$ legged spin ladder oxyhydrides $\mathrm{Sr}_{n+1} \mathrm{~V}_{n} \mathrm{O}_{2 n+1} \mathrm{H}_{n}(n=1,2, . ., \infty)$ (Fig. 1g) ${ }^{90}$.

During the last decade, there has been remarkable progress in physics involving topological phases of matter, for which mixedanion compounds play crucial roles in advancing this field. Binary chalcogenides $\mathrm{Bi}_{2} \mathrm{Se}_{3}$ and $\mathrm{Bi}_{2} \mathrm{Te}_{3}$ were thought to be potential three-dimensional topological insulators, but both suffered from native point defects and unintentional carrier doping. Alloying with these two compounds along with Sb-for-Bi substitution has established a highly insulating bulk and accessible Dirac carriers, accompanied by the observation of a sign change of the Dirac carriers (holes vs electrons) with chemical potential (Fig. 6d) ${ }^{91}$. The precise carrier control has been also utilized to achieve a topological surface state quantum Hall effect (Fig. 6d) ${ }^{92}$.

The layered polar semiconductor BiTeI shows a huge bulk Rashba-type spin splitting (Fig. 6d) that arises from the strong inversion asymmetry along the trigonal $c$-axis induced by distinct covalent $\mathrm{Bi}-\mathrm{Te}$ and ionic $\mathrm{Bi}-\mathrm{I}$ bonds in the facial-BiTe $\mathrm{I}_{3}$ coordination (Fig. 1d $)^{93}$. This built-in bulk polarity induces $2 \mathrm{D}$ 
electronic surface structures with heavy depleted (I-termination) and accumulated (Te-termination) electrons forming $p-n$ junctions (Fig. 6d) ${ }^{94}$. Although BiTeI is a nontopological insulator at ambient pressure, it is proposed that the strong spin-orbit interaction allows a pressure-induced transition to a strong topological insulator, where, due to the broken inversion symmetry, a Weyl semimetal emerges between the two insulating phases ${ }^{95}$.

\section{Outlook}

Increasing interest in solids based on mixed anions is expected to lead to new materials, some of which will make significant contributions to catalysis, energy conversion, and electronic devices, and will ultimately benefit industry in the coming decades. Functionality based on the earth-abundant, light elements usually present as anionic species $(\mathrm{O}, \mathrm{N}, \mathrm{H}, \mathrm{S}, \mathrm{Cl}$, and so on) also offers the advantage of avoiding the inherent scarcity problems of metals, such as lanthanides. The metastability of mixed-anion compounds increases the complexity of synthesis and can limit the ways in which these materials can be used in devices. Therefore, chemically stabilizing these phases has to be considered when they are adapted for applications.

Synthetically, there will still be much room to develop methodologies. For example, multiple synthetic tools are used together (e.g., topochemical reaction under high pressure) or in a multistep process (e.g., solvothermal reaction followed by electrochemical reaction), both providing further platforms to manipulate multiple anions in extended solids. One of the important challenges is how to control anion order/disorderone idea may be to utilize the size flexibility of hydride (Fig. 2a) to induce an order-disorder transition by (chemical) pressure. Furthermore, exploratory synthesis can be joined with computational tools ranging from DFT calculations to machine learning to expedite the screening process.

Regarding catalysis, this review has focused on visible-lightdriven water splitting, but we believe that mixed-anion compounds can offer a variety of new possibilities, which would provide a large impact on chemical industry. In fact, an oxyhydride $\mathrm{BaTiO}_{2.5} \mathrm{H}_{0.5}$ has been very recently found to be an active catalyst for ammonia synthesis, which is remarkable given that $\mathrm{Ti}$ has been regarded as a 'dead' element in terms of heterogeneous catalysis $^{96}$. The lability of hydride (Fig. 1f) may be responsible for this catalytic activity. Introduction of a new anion, not limited to hydride, into oxides will therefore be a useful strategy to explore a new catalytic function of 'inert' oxides. In situ and in operando analytic techniques will benefit and improve our understanding of these functions arising from mixed anion materials. The integration of DFT and machine learning and experiment can lead to the most likely reaction mechanism, and also provide new concepts or guiding principles to be added in Figs. 1 and 2.

Most functional mixed-anion materials known to date, and providing the focus of this review, are oxide based, although nonoxide mixed-anion systems may also provide novel phases and phenomena ${ }^{83,97-99}$. The additional inclusion of molecular anions (e.g., $\mathrm{O}_{2}^{-}, \mathrm{BH}_{4}^{-}$) can give rise to new aspects of anion-based

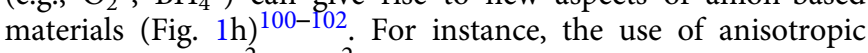
anions, such as $\mathrm{O}_{2}{ }^{2-}$ or $\mathrm{S}_{2}{ }^{2-}$ will result in local symmetry breaking and alter the hybridization with coordinating cations. Furthermore, mixed anions in surface, 2D-sheet materials $s^{99}$, interfaces, porous and nano materials, and amorphous systems are an important area for both fundamental and applied research.

There is still much to discover about the scientific principles and technological applications of mixed-anion materials. It means that the future prospects of mixed-anion materials are largely unknown at this time and this is what precisely makes the field so interesting moving forward. P. W. Anderson famously proposed that 'More is Different'; in the world of anion-based materials we analogously conclude that 'Mixed is Different'.

Received: 30 October 2017 Accepted: 2 January 2018

Published online: 22 February 2018

\section{References}

1. Cronyn, M. W. The proper place for hydrogen in the periodic table. J. Chem Edu. 80, 947-951 (2003).

2. Ebbinghaus, S. G. et al. Perovskite-related oxynitrides - Recent developments in synthesis, characterisation and investigations of physical properties. Prog. Solid State Chem. 37, 173-205 (2009).

3. Kim, Y.-I., Woodward, P. M., Baba-Kishi, K. Z. \& Tai, C. W. Characterization of the structural, optical, and dielectric properties of oxynitride perovskites $\mathrm{AMO}_{2} \mathrm{~N}(\mathrm{~A}=\mathrm{Ba}, \mathrm{Sr}, \mathrm{Ca} ; \mathrm{M}=\mathrm{Ta}, \mathrm{Nb})$. Chem. Mater. 16, 1267-1276 (2004).

4. Sanjaya Ranmohotti, K. G., Josepha, E., Choi, J., Zhang, J. \& Wiley, J. B. Topochemical manipulation of perovskites: Low-temperature reaction strategies for directing structure and properties. Adv. Mater. 23, 442-460 (2011).

5. Tsujimoto, Y., Yamaura, K. \& Takayama-Muromachi, E. Oxyfluoride chemistry of layered perovskite compounds. Appl. Sci. 2, 206-219 (2012).

6. Kobayashi, Y., Tian, M., Eguchi, M. \& Mallouk, T. E. Ion-exchangeable, electronically conducting layered perovskite oxyfluorides. J. Am. Chem. Soc. 131, 9849-9855 (2009).

7. Hayward, M. A. et al. The hydride anion in an extended transition metal oxide array: $\mathrm{LaSrCoO}_{3} \mathrm{H}_{0.7}$. Science 295, 1882-1884 (2002). The first report on the transition-metal oxyhydride using topochemical reactions.

8. Bridges, C. et al. Electronic structure, magnetic ordering, and formation pathway of the transition metal oxide hydride $\mathrm{LaSrCoO}_{3} \mathrm{H}_{0.7}$. J. Am. Chem. Soc. 127, 5996-6011 (2005).

9. Yamamoto, T. et al. The role of $\pi$-blocking hydride ligands in a pressureinduced insulator-to-metal phase transition in $\mathrm{SrVO}_{2} \mathrm{H}$. Nat. Commun. 8, 1212 (2017).

10. Kobayashi, Y. et al. An oxyhydride of $\mathrm{BaTiO}_{3}$ exhibiting hydride exchange and electronic conductivity. Nat. Mater. 11, 507-511 (2012). This report demonstrated the hydride labilety in an oxyhydride, a property later used to access new mixed-anion compounds or as a catalyst.

11. Tassel, C. et al. Direct synthesis of chromium perovskite oxyhydride with a high magnetic transition temperature. Angew. Chem. Int. Ed. 53, 10377-10380 (2014).

12. Zhang, Y., Verbraeken, M. C., Tassel, C. \& Kageyama, H. in Handbook of Solid State Chemistry(eds Dronskowski, R., Kikkawa, S. \& Stein, A.) Ch. 12 (Wiley, Hoboken, New Jersey, 2017).

13. Yajima, T. et al. A labile hydride strategy for the synthesis of heavily nitridized $\mathrm{BaTiO}_{3}$. Nat. Chem. 7, 1017-1023 (2015).

14. Masuda, N. et al. Hydride in $\mathrm{BaTiO}_{2.5} \mathrm{H}_{0.5}$ : A labile ligand in solid state chemistry. J. Am. Chem. Soc. 137, 15315-15321 (2015).

15. Rabenau, A. The role of hydrothermal synthesis in preparative chemistry. Angew. Chem. Int. Ed. 24, 1026-1040 (1985).

16. Tressaud, A. \& Poeppelmeier, K. R. (eds). Photonic and Electronic Properties of Fluoride Materials: Progress in Fluorine Science Series (Elsevier, Amsterdam, 2016).

17. Talanov, M. V., Shirokova, V. B. \& Talanov, V. M. Anion order in perovskites: A group-theoretical analysis. Acta Cryst. A72, 222-235 (2016).

18. Hwang, H. Y. et al. Emergent phenomena at oxide interfaces. Nat. Mater. 11, 103-113 (2012).

19. Suzuki, A. et al. High-mobility electron conduction in oxynitride: Anatase TaON. Chem. Mater. 26, 393-396 (2014).

20. Oka, D. et al. Possible ferroelectricity in perovskite oxynitride $\mathrm{SrTaO}_{2} \mathrm{~N}$ epitaxial thin films. Sci. Rep. 4, 4987 (2014).

21. Bouilly, G. et al. Substrate induced anion rearrangement in epitaxial thin film of $\mathrm{LaSrCoO}_{4-x} \mathrm{H}_{x}$. CrystEngComm 16, 9669-9674 (2014).

22. Soignard, E. et al. Spinel-structured gallium oxynitride $\left(\mathrm{Ga}_{3} \mathrm{O}_{3} \mathrm{~N}\right)$ synthesis and characterization: An experimental and theoretical study. Chem. Mater. 17, 5465-5472 (2005)

23. Yang, M. et al. Direct solid-state synthesis at high pressures of new mixedmetal oxynitrides: $\mathrm{RZrO}_{2} \mathrm{~N}(\mathrm{R}=\mathrm{Pr}, \mathrm{Nd}$, and $\mathrm{Sm})$. Inorg. Chem. 48, 11498-11500 (2009).

24. Tassel, C. et al. $\mathrm{MnTaO}_{2} \mathrm{~N}$ : Polar $\mathrm{LiNbO}_{3}$-type oxynitride with a helical spin order. Angew. Chem. Int. Ed. 54, 516-521 (2015).

25. Kuno, Y. et al. Stabilized high-temperature $\mathrm{LiNbO}_{3}$-type structure. J. Am. Chem. Soc. 138, 15950-15955 (2016). 
26. Bhat, S. et al. High-pressure synthesis of novel boron oxynitride $\mathrm{B}_{6} \mathrm{~N}_{4} \mathrm{O}_{3}$ with sphalerite type structure. Chem. Mater. 27, 5907-5914 (2015).

27. Woodhead, K. et al. High pressure polymorphism of $\beta-\mathrm{TaON}$. Dalton Trans. 43, 9647-9654 (2014).

28. Seko, A., Koyama, Y. \& Tanaka, I. Cluster expansion method for multicomponent systems based on optimal selection of structures for densityfunctional theory calculations. Phys. Rev. B 80, 165122 (2009).

29. Zunger, A., Wei, S.-H., Ferreira, L. G. \& Bernard, J. E. Special quasirandom structures. Phys. Rev. Lett. 65, 353 (1990).

30. Meredig, B. \& Wolverton, C. A hybrid computational-experimental approach for automated crystal structure solution. Nat. Mater. 12, 123-127 (2013).

31. Waghmare, U. V. First-principles theory, coarse-grained models, and simulations of ferroelectrics. Acc. Chem. Res. 47, 3242-3249 (2014).

32. Brown, I. D. Recent developments in the methods and applications of the bond valence model. Chem. Rev. 109, 6858-6919 (2009).

33. Fuertes, A. Prediction of anion distributions using Pauling's second rule. Inorg. Chem. 45, 9640-9642 (2006).

34. Yang, M. et al. Anion order in perovskite oxynitrides. Nat. Chem. 3, 47-52 (2011). This report proposed a correlated disorder in mixed anion perovskites, classified later as an "open order".

35. Clark, L., Oró-Solé, J., Knight, K. S., Fuertes, A. \& Attfield, J. P. Thermally robust anion-chain order in oxynitride perovskites. Chem. Mater. 25, 5004-5011 (2013).

36. Oró-Solé, J., Clark, L., Bonin, W., Attfield, J. P. \& Fuertes, A. Anion-ordered chains in a d perovskite oxynitride: $\mathrm{NdVO}_{2} \mathrm{~N}$. Chem. Commun. 49, 2430-2432 (2013).

37. Oró-Solé, J. et al. Synthesis, anion order and magnetic properties of $\mathrm{RVO}_{3-x} \mathrm{~N}_{x}$ perovskites ( $\mathrm{R}=\mathrm{La}, \mathrm{Pr}, \mathrm{Nd} ; 0 \leq x \leq 1)$. J. Mater. Chem. C. 2, 2212-2220 (2014).

38. Wang, P. L. \& Werner, P.-E. Study on the structure of N-containing melilite $\mathrm{Y}_{2} \mathrm{Si}_{3} \mathrm{O}_{3} \mathrm{~N}_{4}$ and $\mathrm{Nd}_{2} \mathrm{Si}_{25} \mathrm{Al}_{0.5} \mathrm{O}_{3.5} \mathrm{~N}_{3.5}$. J. Mater. Sci. 32, 1925-1929 (1997).

39. Keen, D. A. \& Goodwin, A. L. The crystallography of correlated disorder. Nature 521, 303-309 (2015).

40. Page, $\mathrm{K}$. et al. Local atomic ordering in $\mathrm{BaTaO}_{2} \mathrm{~N}$ studied by neutron pair distribution function analysis and density functional theory. Chem. Mater. 19, 4037-4042 (2007). The first study applying the PDF method to mixed anion compounds, revealing a cis coordination preference in perovskite oxynitrides.

41. Oka, D. et al. Strain engineering for anion arrangement in perovskite oxynitrides. ACS Nano 11, 3860-3866 (2017).

42. Goto, Y. et al. Pressure stabilized cubic perovskite oxyhydride $\mathrm{BaScO}_{2} \mathrm{H}$. Inorg. Chem. 56, 4840-4845 (2017).

43. Smith, M. E. Observation of mixed $\mathrm{Al}(\mathrm{O}, \mathrm{N})_{4}$ structural units by ${ }^{27} \mathrm{Al}$ magic angle spinning NMR. J. Phys. Chem. 96, 1444-1448 (1992).

44. Cozzan, C. et al. Structural evolution and atom clustering in $\beta$-SiAlON: $\beta$ $\mathrm{Si}_{6-\mathrm{z}} \mathrm{Al}_{z} \mathrm{O}_{z} \mathrm{~N}_{8-\mathrm{z}}$. Inorg. Chem. 56, 2153-2158 (2017).

45. Hayashi, K., Sushko, P. V., Hashimoto, Y., Shluger, A. L. \& Hosono, H. Hydride ions in oxide hosts hidden by hydroxide ions. Nat. Commun. 5, 3515 (2014). This paper reports local environment effects of hydride ion on nuclear magnetic resonance and relevant methodology for hydride ion idenditification.

46. Salasin, J. \& Rawn, C. Structure property relationships and cationic doping in $\left[\mathrm{Ca}_{24} \mathrm{Al}_{28} \mathrm{O}_{64}\right]^{4+}$ framework: A reveiw. Crystals 7, 143 (2017).

47. Bielanski, A. \& Haber, J. Oxygen in catalysis on transition metal oxides. Catal. Rev. Sci. Eng. 19, 1-41 (1979).

48. Hayashi, K., Sushko, P. V., Shluger, A. L., Hirano, M. \& Hosono, H. Hydride ion as a two-electron donor in a nanoporous crystalline semiconductor $12 \mathrm{CaO} \cdot 7 \mathrm{Al}_{2} \mathrm{O}_{3}$. J. Phys. Chem. B 109, 23836-23842 (2005).

49. Matsuishi, S., Hayashi, K., Hirano, M. \& Hosono, H. Hydride ion as photoelectron donor in a microporous crystal. J. Am. Chem. Soc. 127, 12454-12455 (2005).

50. Jansen, M. \& Letschert, H. P. Inorganic yellow-red pigments without toxic metals. Nature 404, 980-982 (2000). Report of an oxynitride solid solution demonstrating variable band gap (valence band maximum) and thus tunable colours.

51. Scaife, D. E. Oxide semiconductors in photoelectrochemical conversion of solar energy. Sol. Energy 25, 41-54 (1980).

52. Hitoki, G. et al An oxynitride, $\mathrm{TaON}$, as an efficient water oxidation photocatalyst under visible light irradiation $(\lambda \leq 500 \mathrm{~nm})$. Chem. Commun. 1698-1699 (2002).

53. Ishikawa, A. et al. Oxysulfide $\mathrm{Sm}_{2} \mathrm{Ti}_{2} \mathrm{~S}_{2} \mathrm{O}_{5}$ as a stable photocatalyst for water oxidation and reduction under visible light irradiation $(\lambda \leq 650 \mathrm{~nm}) . \mathrm{J}$. Am. Chem. Soc. 124, 13547-13553 (2002).

54. Maeda, K., Lu, D. \& Domen, K. Direct water splitting into hydrogen and oxygen under visible light using modified TaON photocatalysts with $\mathrm{d}^{0}$ electronic configuration. Chem. Eur. J. 19, 4986-4991 (2013).

55. Maeda, K., Higashi, M., Lu, D., Abe, R. \& Domen, K. Efficient nonsacrificial water splitting through two-step photoexcitation by visible light using a modified oxynitride as a hydrogen evolution photocatalyst. J. Am. Chem. Soc. 132, 5858-5868 (2010).
56. Sekizawa, K., Maeda, K., Domen, K., Koike, K. \& Ishitani, O. Artificial Zscheme constructed with a supramolecular metal complex and semiconductor for the photocatalytic reduction of $\mathrm{CO}_{2}$. J. Am. Chem. Soc. 135, 4596-4599 (2013).

57. Charles, N. \& Rondinelli, J. M. Assessing exchange-correlation functional performance for structure and property predictions of oxyfluoride compounds from first principles. Phys. Rev. B 94, 174108 (2016).

58. Sun, J. et al. Accurate first-principles structures and energies of diversely bonded systems from an efficient density functional. Nat. Chem. 8, 831-836 (2016).

59. Maeda, K. et al. GaN:ZnO Solid solution as a photocatalyst for visible-lightdriven overall water splitting. J. Am. Chem. Soc. 127, 8286-8287 (2005). This is the first reproducible example of visible-light water splitting, and triggered research activity in this field.

60. Ohno, T., Bai, L., Hisatomi, T., Maeda, K. \& Domen, K. Photocatalytic water splitting using modified GaN:ZnO solid solution under visible light: long-time operation and regeneration of activity. J. Am. Chem. Soc. 134, 8254-8259 (2012).

61. Fujito, $\mathrm{H}$. et al. Layered perovskite oxychloride $\mathrm{Bi}_{4} \mathrm{NbO}_{8} \mathrm{Cl}$ : a stable visible light responsive photocatalyst for water splitting. J. Am. Chem. Soc. 138, 2082-2085 (2016).

62. Kato, D. et al. Valence band engineering of layered bismuth oxyhalides toward stable visible-light water splitting: Madulung site potential analysis. J. Am. Chem. Soc. 139, 18725-18731 (2017).

63. Hirosaki, N., Xie, R.-J. \& Kimoto, K. Characterization and properties of greenemitting $\beta$-SiAlON:Eu ${ }^{2+}$ powder phosphors for white light-emitting diodes. Appl. Phys. Lett. 86, 211905 (2005).

64. Zeuner, M., Pagano, S. \& Schnick, W. Nitridosilicates and oxonitridosilicates: from ceramic materials to structural and functional diversity. Angew. Chem. Int. Ed. 50, 7754-7775 (2011)

65. Chen, W. T., Sheu, H. S., Liu, R. S. \& Attfield, J. P. Cation-size-mismatch tuning of photoluminescence in oxynitride phosphors. J. Am. Chem. Soc. 134, 8022-8025 (2012).

66. Park, S. \& Vogt, T. Luminescent phosphors, based on rare earth substituted oxyfluorides in the $\mathrm{A}(1)_{3-x} \mathrm{~A}(2)_{x} M \mathrm{O}_{4} \mathrm{~F}$ family with $\mathrm{A}(1) / \mathrm{A}(2)=\mathrm{Sr}, \mathrm{Ca}, \mathrm{Ba}$ and $M=\mathrm{Al}$, Ga. J. Lumin. 129, 952-957 (2009).

67. Im, W. B. et al. $\mathrm{Sr}_{2.975-x} \mathrm{Ba}_{x} \mathrm{Ce}_{0.025} \mathrm{AlO}_{4} \mathrm{~F}$ : a highly efficient green-emitting oxyfluoride phosphor for solid state white lighting. Chem. Mater. 22, 2842-2849 (2010).

68. Hirai, D. et al. "Visible" 5d orbital states in a pleochroic oxychloride. J. Am. Chem. Soc. 139, 10784-10789 (2017).

69. Freysoldt, C. et al. First-principles calculations for point defects in solids. Rev Mod. Phys. 86, 253-305 (2014).

70. Imanaka, N., Okamoto, K. \& Adachi, G. Water-insoluble lanthanum oxychloride-based solid electrolytes with ultra-high chloride ion conductivity. Angew. Chem. Int. Ed. 41, 3890-3892 (2002).

71. Kobayashi, G. et al. Pure $\mathrm{H}^{-}$conduction in oxyhydrides. Science 351, 1314-1317 (2016). The first report on pure $H^{-}$conduction in oxyhydrides.

72. Julien, C., Mauger, A. \& Groult, H. in Advanced Fluoride-based Materials for Energy Conversion (eds Nakajima, T. \& Groult, H.) Ch. 4 (Elsevier, Amsterdam, 2015).

73. Sauvage, F. D. R. et al. $\mathrm{Ag}_{4} \mathrm{~V}_{2} \mathrm{O}_{6} \mathrm{~F}_{2}$ (SVOF): A high silver density phase and potential new cathode material for implantable cardioverter defibrillators. Inorg. Chem. 47, 8464-8472 (2008).

74. Sauvage, Fdr, Bodenez, V., Tarascon, J.-M. \& Poeppelmeier, K. R. Roomtemperature synthesis leading to nanocrystalline $\mathrm{Ag}_{2} \mathrm{~V}_{4} \mathrm{O}_{11}$. J. Am. Chem. Soc 132, 6778-6782 (2010).

75. Aurbach, D. et al. Prototype systems for rechargeable magnesium batteries. Nature 407, 724-727 (2000)

76. Incorvati, J. T. et al. Reversible magnesium intercalation into a layered oxyfluoride cathode. Chem. Mater. 28, 17-20 (2016).

77. Wan, L. F., Incorvati, J. T., Poppelmeier, K. R. \& Prendergast, D. Building a fast lane for $\mathrm{Mg}$ diffusion in $\alpha-\mathrm{MoO}_{3}$ by fluorine doping. Chem. Mater. 28, 6900-6908 (2016)

78. Zhao, L. D. et al. $\mathrm{Bi}_{1-x} \mathrm{Sr}_{x} \mathrm{CuSeO}$ oxyselenides as promising thermoelectric materials. Appl. Phys. Lett. 97, 092118 (2010).

79. Hume-Rothery, W. \& Powell, H. M. On the theory of super-lattice structures in alloys. Z. Krist. 91, 23-47 (1935)

80. Wu, H. J. et al. Broad temperature plateau for thermoelectric figure of merit $Z T>2$ in phase-separated $\mathrm{PbTe}_{0.7} \mathrm{~S}_{0.3}$. Nat. Commun. 5, 4515 (2014).

81. Pei, Y. et al. Convergence of electronic bands for high performance bulk thermoelectrics. Nature 476, 66 (2011).

82. Pöttgen, R. \& Johrendt, D. Materials with ZrCuSiAs-type structure. $Z$. Naturforsch. B. 63, 1135-1148 (2014).

83. Yamanaka, S. Intercalation and superconductivity in ternary layer structured metal nitride halides ( $M \mathrm{~N} X: M=\mathrm{Ti}, \mathrm{Zr}, \mathrm{Hf} ; X=\mathrm{Cl}, \mathrm{Br}$, I). J. Mater. Chem. 20, 2922-2933 (2010) 
84. Al-Mamouri, M., Edwards, P. P., Greaves, C. \& Slaski, M. Synthesis and superconducting properties of the strontium copper oxy-fluoride $\mathrm{Sr}_{2} \mathrm{CuO}_{2} \mathrm{~F}_{2}$ $+\delta$. Nature 369, 382-384 (1994).

85. Hiroi, Z., Kobayashi, N. \& Takano, M. Probable hole-doped superconductivity without apical oxygens in $\left(\mathrm{Ca}, \mathrm{Na}_{2} \mathrm{CuO}_{2} \mathrm{Cl}_{2}\right.$. Nature 371, 139-141 (1994).

86. Aidoudi, F. H. et al. An ionothermally prepared $S=1 / 2$ vanadium oxyfluoride kagome lattice. Nat. Chem. 3, 801-806 (2011).

87. Shores, M. P., Nytko, E. A., Bartlett, B. M. \& Nocera, D. G. A structurally perfect $S=1 / 2$ kagomé antiferromagnet. J. Am. Chem. Soc. 127, 13462-13463 (2005). The hydrothermal synthesis of a long-awaited structurally perfect kagomé lattice.

88. Han, T.-H. et al. Fractionalized excitations in the spin-liquid state of a kagomé-lattice antiferromagnet. Nature 492, 406-410 (2012).

89. Okamoto, Y., Yoshida, H. \& Hiroi, Z. Vesignieite $\mathrm{BaCu}_{3} \mathrm{~V}_{2} \mathrm{O}_{8}(\mathrm{OH})_{2}$ as a candidate spin-1/2 kagomé antiferromagnet. J. Phys. Soc. Jpn. 78, 033701 (2009).

90. Romero, F. D. et al. Strontium vanadium oxide-hydrides: "Square-planar" twoelectron phases. Angew. Chem. Int. Ed. 53, 1-5 (2014).

91. Arakaneu, T. et al. Tunable Dirac cone in the topological insulator $\mathrm{Bi}_{2-x} \mathrm{Sb}_{x} \mathrm{Te}_{3-y} \mathrm{Se}_{y}$. Nat. Commun. 3, 636 (2012).

92. $\mathrm{Xu}, \mathrm{Y}$. et al. Observation of topological surface state quantum Hall effect in an intrinsic three-dimensional topological insulator. Nat. Phys. 10, 956-963 (2014).

93. Ishizaka, K. et al. Giant Rashba-type spin splitting in bulk BiTeI. Nat. Mater. 10, 521-526 (2011). Report of huge spin-orbit interaction effect derived from polar $\mathrm{BiTe}_{3} \mathrm{I}_{3}$ octahedral coordination.

94. Kohsaka, Y., Kanou, M., Takagi, H., Hanaguri, T. \& Sasagawa, T. Imaging ambipolar two-dimensional carriers induced by the spontaneous. Phys. Rev. B 91, 245312 (2013).

95. Murakami, S., Hirayama, M., Okugawa, R. \& Miyake, T. Emergence of topological semimetals in gap closing in semiconductors without inversion symmetry. Sci. Adv. 3, e1602680 (2017).

96. Kobayashi, Y. et al. Titanium-based hydrides as heterogeneous catalysts for ammonia synthesis. J. Am. Chem. Soc. 139, 18240-18246 (2017).

97. Yajima, T. et al. Selective and low temperature transition metal intercalation in the layered tellurides. Nat. Commun. 7, 13809 (2016).

98. Lingampalli, S. R., Manjunath, K., Shenoy, S., Waghmare, U. V. \& Rao, C. N. R. $\mathrm{Zn}_{2} \mathrm{NF}$ and related analogues of ZnO. J. Am. Chem. Soc. 138, 8228-8234 (2016).

99. Anasori, B. \& Gogotsi, Y. 2D metal carbides and nitrides (MXenes) for energy storage. Nat. Rev. Mater. 2, 16098 (2017).

100. Tang, X., Xiang, H., Liu, X., Speldrich, M. \& Dronskowski, R. A ferromagnetic carboaiimide: $\mathrm{Cr}_{2}(\mathrm{NCN})_{3}$. Angew. Chem. Int. Ed. 49, 4738-4742 (2010).

101. Pralong, V. et al. Oxygen excess in the "114" cobaltite hexagonal structure: The ferrimagnet $\mathrm{CaBaCo}_{4} \mathrm{O}_{7.50}$. J. Solid State Chem. 184, 2588-2594 (2011).

102. Sathiya, M. et al. Reversible anionic redox chemistry in high-capacity layeredoxide electrodes. Nat. Mater. 12, 827-835 (2013)

103. Clarke, S. J. et al. Structures, physical properties, and chemistry of layered oxychalcogenides and oxypnictides. Inorg. Chem. 47, 8473-8486 (2008).

104. Kamihara, Y., Watanabe, T., Hirano, M. \& Hosono, H. Iron-based layered superconductor $\mathrm{La}\left[\mathrm{O}_{1-x} \mathrm{~F}_{x}\right] \mathrm{FeAs}(x=0.05-0.12)$ with $T_{\mathrm{c}}=26 \mathrm{~K}$. J. Am. Chem. Soc. 130, 3296-3297 (2008).
105. Iwazaki, Y., Suzuki, T. \& Tsuneyuki, S. Negatively charged hydrogen at oxygen-vacancy sites in $\mathrm{BaTiO}_{3}$ : Density-functional calculation. J. Appl. Phys. 108, 083705 (2010).

106. Weast, R. C. (ed.) Handbook of Chemistry and Physics 64th edn Tables of Isotopes B-232 (CRC Press, Boca Raton, Florida, 1983-1984).

107. Atkins, P. et al. Shriver and Atkins's Inorganic Chemistry 5th edn (Oxford University Press, Oxford, 2010).

108. Shannon, R. D. Revised effective ionic radii and systematic studies of interatomic distances in halides and chalcogenides. Acta Cryst. A32, 751-767 (1976).

109. Libowitz, G. G. The Solid State Chemistry of Binary Metal Hydrides (W.A. Benjamin Inc., New York, 1965).

110. Fowler, P. W. \& Tole, P. Anionic polarisability in halides and chalcogenides. Rev. Solid State Sci. 5, 149-176 (1991).

111. Shannon, R. D. \& Fischer, R. X. Empirical electronic polarizabilities of ions for the prediction and interpretation of refractive indices: Oxides and oxysalts. Am. Mineral. 101, 2288-2300 (2016).

\section{Acknowledgements}

We thank Dr. Fumitaka Takeiri, Prof. Kyoko Ishizaka, Dr. Kohei Miyazaki, Prof. Shuichi Murakami, Dr. Yoji Kobayashi, Dr. Hiraku Ogino, and Prof. Yutaka Ueda for helpful discussions. Financial support from the JSPS Grant-in-Aid for Scientific Research on Innovative Areas "Mixed anion" (16H06439, 16H06440, 16H06441, and 16K21724) and CREST (JPMJCR1421) from JST is acknowledged. K.R.P. and J.M.R. were supported by the National Science Foundation's MRSEC program (DMR-1720139) at the Materials Research Center of Northwestern University.

\section{Additional information}

Competing interests: The authors declare no competing financial interests.

Reprints and permission information is available online at http://npg.nature.com/ reprintsandpermissions/

Publisher's note: Springer Nature remains neutral with regard to jurisdictional claims in published maps and institutional affiliations.

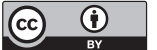

Open Access This article is licensed under a Creative Commons Attribution 4.0 International License, which permits use, sharing, adaptation, distribution and reproduction in any medium or format, as long as you give appropriate credit to the original author(s) and the source, provide a link to the Creative Commons license, and indicate if changes were made. The images or other third party material in this article are included in the article's Creative Commons license, unless indicated otherwise in a credit line to the material. If material is not included in the article's Creative Commons license and your intended use is not permitted by statutory regulation or exceeds the permitted use, you will need to obtain permission directly from the copyright holder. To view a copy of this license, visit http://creativecommons.org/licenses/by/4.0/.

(C) The Author(s) 2018 